\title{
Investigation of Deformation Twinning under Complex Stress States in a Rolled
}

\section{Magnesium Alloy}

\author{
Wei $\mathrm{Wu}^{1}$, Chih-Pin Chuang ${ }^{2}$, Dongxiao Qiao ${ }^{3}$, Yang $\mathrm{Ren}^{2}$, and Ke $\mathrm{An}^{1}$ \\ 1. Chemical and Engineering Materials Division, Oak Ridge National Laboratory, Oak Ridge, \\ TN 37831, USA \\ 2. X-ray Science Division, Argonne National Laboratory, Argonne, IL 60439, USA \\ 3. Tsinghua University, Haidian, Beijing, China
}

\section{*Corresponding authors}

Ke An, Ph.D.

Lead Scientist

Chemical and Engineering Materials Division

Oak Ridge National Laboratory

1 Bethel Valley Rd

Oak Ridge

TN 37831, USA

Office: $+1-865-919-5226$

Fax: +1-865-574-6080

E-mail: kean@ornl.gov 


\begin{abstract}
:
A specially designed semi-circular notch specimen was employed in the current study to generate the various strain conditions, including uniaxial, biaxial, shear, and plane strains, which was utilized to explore the evolution of different deformation twinning systems under complex loading conditions. Using in situ synchrotron X-ray diffraction mapping method, it was found that the extensive double twins were activated during loading, while nearly no extension twinning activity was detected. After the formation of $\{10.1\}$ and $\{10.3\}$ compression twins, they transformed into $\{10.1\}-\{10.2\}$ and $\{10.3\}-\{10.2\}$ double twins instantaneously at the early stage of deformation. The lattice strain evolutions in different $h k l s$ were mapped at selected load levels during the loading-unloading sequence. The relationship between the macroscopic straining and microscopic response was established.
\end{abstract}

Keywords: Metals and alloys; Mechanical properties; X-ray diffraction; Microstructure 


\section{Introduction}

Magnesium (Mg) alloys are the lightest among commercial metals for the structural applications, which has drawn great attentions from academic society and transportation industries due to the combined properties of high strength-to-weight ratio and high specific stiffness [1, 2]. Compared with casting $\mathrm{Mg}$ alloys, wrought $\mathrm{Mg}$ alloys exhibit superior mechanical properties and fatigue resistance owing to their defect-free nature [3]. The mechanical properties of wrought $\mathrm{Mg}$ alloys can be further improved through heat-treatment, grain refinement, and rare earth element addition [4-10]. Therefore, the study of deformation behavior of wrought $\mathrm{Mg}$ alloys is inevitable for promoting the wide applications of $\mathrm{Mg}$ alloys as load-bearing components.

Mg has a hexagonal close-packed (HCP) crystal structure with a limited number of slip systems leading to an anisotropic plastic deformation behavior [11, 12]. It has been established that $\{00.2\}<11.0>$ basal $<\mathrm{a}>$ slip and $\{10.2\}<10.1>$ extension twinning are the two easy deformation modes in the HCP-structured $\mathrm{Mg}[13,14]$. The $\{10.2\}<10.1>$ extension twinning can be activated by tension along c-axis and compression perpendicular to the c-axis, which

results in a sudden re-orientation of parent grains by approximately $86.3^{\circ}[15,16]$. A plateau is usually perceived in stress-strain curve during the extension twinning dominated deformation, followed by a rapid strain hardening once the extension twinning dominated deformation exhausts, which leads to an early fracture. Comprehensive researches have been concentrated on the $\{10.2\}<10.1>$ extension twinning in highly textured wrought $\mathrm{Mg}$ alloy during uniaxial tension, compression, and cyclic straining in the past two decades [17-25]. 
Besides the $\{10.2\}<10.1>$ extension twinning, there are several twinning systems in the HCP-structured Mg, including the $\{10.1\}$ and $\{10.3\}$ contraction twinning and the $\{10.1\}-\{10.2\}$ and $\{10.3\}-\{10.2\}$ double twinning [26-29]. For the $\{10.1\}-\{10.2\}$ double twinning system, there are four possible variants (type 1, type2, type3, and type4) of double twinning [26]. When the HCP-structured crystal experiences compressive stress along the c-axis or tensile stress perpendicular to the c-axis, it is a favorable stress state for the initiation of the $\{10.1\}$ or $\{10.3\}$ contraction twins. After the formation of the $\{10.1\}$ or $\{10.3\}$ contraction twins, the $\{10.2\}$ secondary extension twins will be activated, because the stress state that favors the contraction twinning also facilitates the secondary extension twinning within the primary twin domain [30]. It has been reported that the compression twinning and double-twinning occurred after necking, indicating that large plastic deformation is required [31]. Compared with the research on extension twinning, studies focused on contraction twinning and double twinning are rare. Moreover, the evolution of compression twinning and double twinning in the bulk sample during in situ deformation remains unknown.

In reality, the structural components usually suffer from the complex loading condition during service other than simple tension or compression. In addition, during sheet metal forming, the materials are under complex multiaxial deformation process and many twinning/slip systems would be triggered. In the current study, a specially designed semi-circular notch sample was exploited to generate the strain/stress concentration around the notch to facilitate the activation of compression twinning and double-twinning deformation. Moreover, the complex biaxial stress states were produced around the notch, which was utilized for characterizing the correlation between the complex strain states and different deformation twinning systems. To the authors' best knowledge, the current study is the first attempt to characterize the compression twinning 
and double twinning deformation behavior in the HCP-structured $\mathrm{Mg}$ alloy during in situ synchrotron X-ray diffraction mapping under load. In the current paper, we address three critical issues, including, (1) how the different deformation twinning systems evolve under loading? (2) what are the lattice strain and stress distribution during deformation? (3) what is the favorite strain state for each twinning systems? 


\section{Material and Methods}

\subsection{Experimental materials}

A commercial AZ31B Mg rolling plate (a nominal composition of $3.0 \% \mathrm{Al}, 1.0 \% \mathrm{Zn}$, and $\mathrm{Mg}$ as balance, in weight percentage) with typical rolling texture was chosen. The initial texture of the rolling plate was published elsewhere [18]. The sample geometry is illustrated in detail in Fig. 1(a). Two semi-circular edge notches with a diameter of $8 \mathrm{~mm}$ were cut on both sides of the plate dog-bone samples. The axial, transverse, and through thickness directions of specimens were aligned with the rolling direction (RD), normal direction (ND), and transverse direction (TD) of the rolling plate, respectively. The "center of notch" is marked in Fig. 1(a), which will be used throughout paper. After sample machining, all specimens were annealed at $345{ }^{\circ} \mathrm{C}$ for 2 hours to release the residual stress. The average grain size of the annealed sample is approximately $40 \mu \mathrm{m}$.

\subsection{Mapping experiments}

Digital image correlation (DIC) method was employed to map the macroscopic strain evolution during tension. The uniaxial tension experiment was conducted using INSTRON ElectroPuls E-3000 testing system, with a fixed displacement rate of $0.008 \mathrm{~mm} / \mathrm{s}$. A digital camera was operated at 0.5 fps (frame per second) during the in situ measurement. The recorded digital images were analyzed using VIC 2D software to compute the surface strain maps for each captured image.

The synchrotron X-ray diffraction mapping experiment was performed at 11ID-C, Advanced Photon Source (APS), Argonne National Laboratory (ANL). The monochromatic beam with energy of $115 \mathrm{keV}$ was used to conduct the experiment in forward scattering mode. 
The combination of the forward Bragg diffraction geometry and high energy x-ray makes the scattering vector nearly parallel to the surface of the specimen. The beam size of $0.2 \times 0.2 \mathrm{~mm}^{2}$ was used to map out the region of interest (notch area) with step size of $0.2 \mathrm{~mm}$. The attenuation length of $115 \mathrm{keV}$ synchrotron X-ray on AZ31 alloy is $3.55 \mathrm{~cm}$ (calculated using mass attenuation coefficient of $0.159 \mathrm{~cm}^{2} / \mathrm{g}$ and density of $1.77 \mathrm{~g} / \mathrm{cm}^{3}$ for AZ31), which exceeds the thickness of the sample $(2.5 \mathrm{~mm})$ in the present study. Considering the beam size coupled with sample thickness of $2.5 \mathrm{~mm}$ and average grain size of $40 \mu \mathrm{m}$, approximately $1500 \sim 1600$ grains were detected in each measurement. The mapping area is demonstrated in Fig. 1(a). The lattice strain mapping was conducted for the total of eight load levels, i.e., 0, 1000, 1500, 2000, 3000, 2000, 1000, and $0 \mathrm{~N}$, in a single loading-unloading cycle. A cross was marked in the center of the sample as a reference location to ensure that the same area was measured at each load level.

\subsection{Data reduction}

The 2-dimensional (2D) diffraction patterns recorded at the various stages of mechanical loadings from the specimen were taken every $1^{\circ}$ along the azimuthal direction. Selected crystallographic planes were analyzed to obtain the evolution of d-spacing and peak intensity as a function of azimuthal angle for each 2D diffraction image. Peak position, intensity and width were obtained by single-peak fitting procedure using a pseudo-Voigt function in Matlab ${ }^{\circledR}$. The lattice strain (elastic strain) was calculated as

$$
\varepsilon_{h k l}^{\phi}=\frac{d_{h k l}^{\phi}-d_{0, h k l}}{d_{0, h k l}}
$$

where $d_{0, h k l}$ was taken directly from un-strained region of the sample (no external load and away from notch). Traditionally, when the sample has no or slight texture, the 1D diffraction 
pattern sliced from each azimuthal angle is treated as a powder diffraction pattern, and the lattice strain in the loading and transverse directions can be obtained by fitting the 1D pattern in those directions and calculated using above equation. However, for heavily textured material like the one in the present study, one might not have any diffraction signal in loading or transverse direction. The strain in those directions without diffraction signal can be obtained by fitting all data points between the azimuthal angle of $0^{\circ}$ and $360^{\circ}$.

The azimuthal dependent lattice strains from the measurement are determined by the strain state of the material at the measured position. It can be express as

$$
f_{x x} \varepsilon_{x x}+f_{x y} \varepsilon_{x y}+f_{y y} \varepsilon_{y y}+f_{x z} \varepsilon_{x z}+f_{y z} \varepsilon_{y z}+f_{z z} \varepsilon_{z z}=\varepsilon_{h k l}^{\phi}
$$

where $\varepsilon_{i j}$ is the strain tensor component, and $f_{i j}$ is the function of diffraction geometry [32]. The details of the theory can be found in reference [33]. Based on the sample geometry of the present study [the sample width was four times as the sample thickness in Fig. 1(a)], a plane stress condition was assumed as the external load to the thin plate sample was in plane, where $\sigma_{z z}=$ $\sigma_{x z}=\sigma_{y z}=0, \varepsilon_{h k l, x z}=\varepsilon_{h k l, y z}=0$. The equation can be further reduced to

$$
f_{x x} \varepsilon_{h k l, x x}+f_{x y} \varepsilon_{h k l, x y}+f_{y y} \varepsilon_{h k l, y y}+f_{z z} \varepsilon_{h k l, z z}=\varepsilon_{h k l}^{\phi}
$$

where

$$
\begin{aligned}
& f_{x x}=\sin ^{2} \phi \cos ^{2} \theta \\
& f_{x y}=-\sin 2 \phi \cos ^{2} \theta \\
& f_{y y}=\cos ^{2} \phi \cos ^{2} \theta \\
& f_{y z}=-\cos \phi \sin 2 \theta \\
& f_{z z}=\sin ^{2} \theta
\end{aligned}
$$


and $\theta$ is the peak position at azimuthal angle $\phi$. In the plane stress condition, the contribution of $f_{z z} \varepsilon_{h k l, z z}$ term can be neglected due to the small diffraction angle $2 \theta$. As a result, the equation is dominated by the first 3 terms with $\varepsilon_{h k l, \mathrm{xx}}, \varepsilon_{h k l, \mathrm{xy}}$, and $\varepsilon_{h k l, \mathrm{yy}}$. By performing the linear leastsquares regression of all the measured azimuthal-dependent lattice strain, the normal and shear strain components ( $\varepsilon_{h k l, \mathrm{xx}}, \varepsilon_{h k l, \mathrm{xy}}$, and $\left.\varepsilon_{h k l, \mathrm{yy}}\right)$ of the material at the measured positions can be obtained. An example of the fitting can be seen in Fig. X1. This total diffraction line shift regression method allows the determination of the shear component, which cannot be measured directly from diffraction patterns as it does not contribute to the line shift in the shear direction.

\subsection{Data analysis procedure}

The deformation twinning systems, twin plane, and reorientation angles in the HCPstructured Mg alloys are listed in Table 1. The letters ET, CT1, CT2, DT1, and DT2 represent extension twinning, $\{10.1\}$ contraction twinning, $\{10.3\}$ contraction twinning, $\{10.1\}-\{10.2\}$ double twinning, and $\{10.3\}-\{10.2\}$ double twinning, respectively, which will be used throughout the whole paper. The twin plane, and reorientation angles of four possible variants of $\{10.1\}-\{10.2\}$ and $\{10.3\}-\{10.2\}$ double twining are presented in Table 2 and 3 , respectively. The symbols of $\mathrm{T} 1, \mathrm{~T} 2, \mathrm{~T} 3$, and $\mathrm{T} 4$ signify the type 1, type 2, type 3, and type 4 of double twining, respectively. According to the deformation twinning systems in the HCP-structured Mg, the schematic of diffraction peak intensity variation under loading is demonstrated in Fig. 1(b). Before deformation, the (00.2) peak intensity distributes evenly around $0^{\circ}$ and $180^{\circ}$. After deformation, the (00.2) peak intensity decreases near $0^{\circ}$ and $180^{\circ}$, while some peaks appear at certain orientation angles depending on the active deformation twinning modes. For example, if the CT1 was operative during the deformation, a sudden increase of (00.2) diffraction peak intensity would appear at near $303.8^{\circ}$ due to the reorientation angle of CT1 at $56.2^{\circ}$. The 
experimental results of (00.2) peak intensity distribution before and after the deformation are presented in Fig. 1(c). It is obvious that the increase of (00.2) diffraction peak intensity appeared near $123.8^{\circ}$ and $303.8^{\circ}$, stemming from the activation of CT1 (the green solid line). Moreover, two small peaks were observed at approximately $142.5^{\circ}$ and $322.5^{\circ}$, signifying the existence of the DT1_T1 (the magenta solid line). Subsequently, in order to characterize the evolution of deformation twinning during the deformation, the (00.2) peak intensity was summed up at certain orientation angles over $\pm 2^{\circ}$ depending on the deformation twinning systems at each load level, and then subtracting the (00.2) peak intensity at the same orientation angles before the deformation. It is reasonable to rely on the increase of diffraction peak intensity of certain $h k l$ [the (00.2) peak intensity in the current study] to characterize the evolution of various deformation twinning during the deformation. The grain reorientations due to different deformation twinning in the HCP-structured materials are demonstrated in Fig. 2. It is noticed that the grain reorientations of types 3 and 4 double twinning for both DT1 and DT2 are out of the detector diffraction coverage plane, so the types 3 and 4 double twinning behaviors cannot be monitored in the current study. 


\section{Results}

\subsection{Macroscopic strain distribution}

The macroscopic strain distributions of the three strain components at the selected load levels measured by DIC are displayed in Fig. 3. The macroscopic strain distributions were uniform up to $1000 \mathrm{~N}$. When the applied load reached $2000 \mathrm{~N}$, strain concentration was perceived around the notch for all the three strain components. As the sample was further stretched to $3000 \mathrm{~N}$, the strain concentration was found to be more intense in the area close to the notch. Moreover, the Lüders-like band was developed and inclined in an angle of $34.4^{\circ}$ from the vertical direction. The intensive shear strain, which was obtained by DIC, was detected around the notches. In general, the localized macroscopic strain concentration was perceived in the middle of specimen during the deformation.

\subsection{Deformation twinning}

Based on the observation from DIC measurement, a question is raised that what the underlying deformation mechanisms are resulting in the uneven macroscopic strain distribution around the notches. To address this question, the synchrotron X-ray diffraction mapping method was adopted in the current study to investigate the diffraction peak intensity evolution of different $h k l s$ during the in situ loading-unloading sequence.

The diffraction peak intensity evolution of the (10.0) and (00.2) grains in axial and transverse directions at selected load levels is illustrated in Fig. 4. The diffraction peak intensity of (10.0) grains decreased during the loading and recovered after the unloading in the axial direction, as shown in Fig. 4(a)-(d). However, the diffraction peak intensity of (10.0) grains in the transverse direction in Fig. 4(e)-(h) varied little during the loading-unloading sequence. On 
the other hand, the (00.2) diffraction peak intensity remained almost unchanged in the axial direction and varied less significantly than the (10.0) grains in the transverse direction during the loading. After the unloading, the diffraction peak intensity of (00.2) grains remained almost the same. If the extension twinning occurs in the current experimental configuration, the diffraction peak intensity of the (10.0) grains in the loading direction would decrease accompanying with the peak intensity of (10.0) grains increase in the transverse direction, because the extension twinning leads to an approximately $86.3^{\circ}$ grains re-orientation. Additionally, the opposite trend should be observed in the (00.2) grains. Therefore, it indicates that no extension twinning is activated during the deformation. It can be speculated that there must be other active deformation modes resulting in the diffraction peak intensity variation in (10.0) and (00.2) grains.

To explore the activated deformation twinning systems during the plastic deformation, each deformation twinning system was investigated individually using an azithmuthal-dependent intensity distribution. The population and distribution of different deformation twinning systems derived from diffraction peak intensity variation of (00.2) grains at selected load levels are presented in Fig. 5. The CT1 scattered randomly under $2000 \mathrm{~N}$ in Fig. 5(a) and (b). While the load reached to $3000 \mathrm{~N}$, a large amount of CT1 located close to the notch was in a band form along the loading direction in Fig. 5(c). After the unloading, the CT1 remained as illustrated in Fig. 5(d). The CT2 randomly spread during the loading and unloading, as displayed in Fig. 5(e)(h). The ET was only perceived at several random locations in Fig. 5(i)-(1).

The (00.2) peak intensity variations due to the double twinning were examined separately at different load levels, as presented in Fig. 6. It can be noticed that the population of double twinning are much larger than other deformation twins compared with Fig. 5. The DT1_T1 originated from the notch edge above the center of the notch at $1000 \mathrm{~N}$ in Fig. 6(a). When the 
load increased, the distribution of DT1_T1 was in a band shape with an inclined angle of approximately $45^{\circ}$ as shown in Fig. 6(b) and (c). After the unloading, the DT1_T1 remained unchanged in Fig. 6(d). The DT2_T2 was originated in the center of the notch at $1000 \mathrm{~N}$ in Fig. 6(e), and spread into the sample at $2000 \mathrm{~N}$ in an approximately $45^{\circ}$ in Fig. 6(f). When the applied load was $3000 \mathrm{~N}$, a large amount of DT2_T2 were found inside the specimen, while the population of DT2_T2 decreased in the center of the notch in Fig. 6(g). After unloading, the population and distribution remained almost the same in Fig. 6(h). It is noticed that the grain reorientation angles of DT1_T2 and DT2_T1 are very close, approximately $30^{\circ}$, as presented in Table 2 and 3. The (00.2) peak intensity variation resulted from both DT1_T2 and DT2_T1 is illustrated in Fig. 6(i)-(1). The general trend of double twinning evolution is similar to the combination of DT1_T1 and DT2_T2.

\subsection{Local lattice strain distribution}

The lattice strain evolutions of the (10.0) and (00.2) grains in yy (axial) and $\mathrm{xx}$ (transverse) directions during the loading-unloading sequence at selected locations of the specimen near the notch are presented in Fig. 7. For the (10.0) grains in yy direction, the lattice strain decreased at the same load level, when the location changed from the bottom to the top along the curvature. On the other hand, the lattice strain of the (00.2) grains in $\mathrm{xx}$ direction increased and changed from the negative to the positive strain at the same load level when the measurement point moved from the lower right corner to the upper right position. The schematic of the biaxial lattice strain states are illustrated in Fig. 7(a).

The averaged lattice strain distributions of the (10.0) and (00.2) grains in the yy and xx directions at different load levels and sample locations are presented in Fig. 8. Every three data 
values in the vertical direction were averaged. In the yy direction, the compressive residual strains (purple line) were only observed near the notch in Fig. 8(b), (d), and (f). When the measurement points moved from the top to the bottom line, at the maximum load level the lattice strain of the (10.0) grain became higher near the notch (cyan line) during the loading. One the other hand, the residual strain zone size after the unloading became smaller, but the value of the compressive residual strain became larger (purple line). In the $\mathrm{xx}$ direction for the top line in Fig. 8(a), the lattice strains of the (00.2) grains changed from compressive to tensile strain when moving from the middle of the sample to the edge in Fig 8(c). As presented in Fig. 8(g), the lattice strain of the (00.2) grains stayed negative during loading-unloading for the bottom line in Fig. 8(a). In conclusion, not only the lattice strain evolution can be observed at each measurement location, but also the bulk-averaged information can be retrieved by averaging the lattice strain in adjacent locations in the current study.

The local lattice strain distributions of different $h k l s$ in yy and $\mathrm{xx}$ directions are illustrated in Fig. 9. At $1000 \mathrm{~N}$, the lattice strain concentration in yy direction was found in the center of the notch edge for all $h k l s$ in Fig. 9(b), (f), and (j). The relative uniform deformation was observed in the middle of sample. When the load reached $3000 \mathrm{~N}$, the plastic zone became larger and the lattice strain concentration turned to be more intense, as displayed in Fig. 9(c), (g), and (k). It was also found that the lattice strain levels of (10.0) and (11.0) grains were much higher than the (10.1) grains. After the unloading, the compressive residual strains were detected close to the notch edge in all the three groups of grains in the yy direction (marked in red lines), as shown in Fig. 9(d), (h), and (1). Among them, the residual compressive zone size of the (10.1) grains was larger than the other two groups of grains. The evenly distributed tensile residual strains were observed in the sample away from the notch edge in the (10.0) and (11.0) grains (marked in 
purple lines), while the (10.1) grains have nearly zero strain. There is a small transition area (marked in green lines) where the residual strain changed from compressive to tensile residual strain. The similar trend can be found in the (00.2) grains in $\mathrm{xx}$ direction during the loading. However, the majority of the residual strains in the sample was around zero after the unloading in Fig. 9(p). The compressive residual strain was retained in the middle of the sample, while a relatively small tensile residual strain was witnessed on the top right corner on Fig. 9(p).

The internal shear strain distributions of certain interested $h k l s$ at the selected load levels are demonstrated in Fig. 10. Overall, the shear strain originated around the notch edge at $1000 \mathrm{~N}$. When the sample was further pulled to $3000 \mathrm{~N}$, relative large shear strain formed a band aligned with the axial direction close to the notch. Moreover, the shear strain expanded into the sample gradually. It is obvious that the (10.0) and (11.0) grains showed strong shear strain localization around the notch edge at the maximum load in Figs. 10(c) and (o). The uniformly distributed shear strain was observed in the (10.1) grains in Fig. 10(k). The relatively small shear strain concentration was detected in (00.2) grains in Fig. 10(h). After the unloading, the residual shear strain located mostly at the sample notch. The band-shaped distribution of residual shear strain was seen in the (10.0), (00.2), and (11.0) grains, while the residual shear strains of all grains were almost zero inside the specimen as displayed in Figs. 10(d), (h), (l), and (p). The residual shear strain of all four groups of grains at the notch edge changed direction at the maximum load, compared with the shear strain distribution.

\subsection{Stress distribution in different $h k l \mathrm{~s}$}

The stress distribution in different groups of grains was estimated according to the plane stress/strain matrix of generic Hooke's law and the equations are shown below, 


$$
\begin{gathered}
\sigma_{h k l, y y}=\frac{E_{h k l}}{1-v_{h k l}^{2}}\left(\varepsilon_{h k l, y y}+v_{h k l} \varepsilon_{h k l, x x}\right) \\
\sigma_{h k l, x x}=\frac{E_{h k l}}{1-v_{h k l}^{2}}\left(\varepsilon_{h k l, x x}+v_{h k l} \varepsilon_{h k l, y y}\right) \\
\tau_{h k l, x y}=\frac{E_{h k l}}{2\left(1+v_{h k l}\right)} \varepsilon_{h k l, x y}
\end{gathered}
$$

where $\sigma_{h k l, y y}, \sigma_{h k l, x x}$, and $\tau_{h k l, x y}$ are the stress in yy, xx direction and shear stress of certain $h k l$, respectively. The $\varepsilon_{h k l, y y}, \varepsilon_{h k l, x x}$, and $\varepsilon_{h k l, x y}$ are the lattice strain of certain $h k l$ in $\mathrm{yy}, \mathrm{xx}$, and shear directions, respectively. The $E_{h k l}$ and $v_{h k l}$ are the diffraction elastic constants. The materials parameters used in the current study were acquired from the neutron diffraction results by real-time in situ tension and compression experiments of ND, RD, and $45^{\circ}$ to the ND and RD samples $[21,24]$ as shown in Table 4.

The stress variations during the loading-unloading at the selected load levels in certain interested $h k l \mathrm{~s}$ in yy and $\mathrm{xx}$ directions are demonstrated in Fig. 11. It is noticed that the stress evenly spread at $1000 \mathrm{~N}$ in yy directions in the (10.0), (10.1), and (11.0) grains in Figs. 11(b), (f), and (j). At $3000 \mathrm{~N}$, the stress concentration was detected in the center of the notch in yy direction, as displayed in Figs. 11(c), (g), and (k). The stress distribution of the (10.0) grains at $3000 \mathrm{~N}$ was identical to that of the (10.1) grains, while the (11.0) grains took a relatively smaller stress than the other two orientation grains. After unloading to $0 \mathrm{~N}$, the compressive residual stress located near the notch, but the tensile residual stress was observed in the middle of the sample, as shown in Figs. 11(d), (h), and (1). During the loading, the stress of the (00.2) grains in xx direction was relatively uniformly distributed in Figs. 11(m)-(o). At the maximum load level, the tensile stress was observed on the upper side of the sample, while the compressive stress was perceived on the 
lower part of the mapping. After the unloading, the large compressive residual stress was found on the lower side of the specimen, while 0 residual stress was identified in the rest of the sample.

The shear stresses in different $h k l$ s at the selected load levels are demonstrated in Fig. 12. It is obvious that the shear stress concentrated at the area close to the notch at $1000 \mathrm{~N}$ in Figs. 12(b), (f), (j), and (n) for the four groups of grains. When the applied load reached $3000 \mathrm{~N}$, a large amount of shear stress can be distinguished in (10.0) and (11.0) grains near the notch in Figs. 12(c) and (o). Nevertheless the shear stress of (10.1) grains close to the sample notch is the smallest among all four orientations of grains, as presented in Fig. 12(k). Moreover, the shear stresses in the middle of sample were in the opposite directions comparing with the shear stress around the sample notch. After unloading, relatively small residual shear stress was built up near the sample notch, but it was in the opposite direction, as shown in Figs. 12(d), (h), (1), and (p).

The specimen geometry design in the present research produces the complex biaxial strain/stress states around the notch edge, which were utilized to investigate the deformation twinning behavior during deformation, but one disadvantage of the current experiment setup is that the microscopic stress at each location is difficult to measure. By assuming the isotropic condition, the stress states, $\sigma_{\mathrm{yy}}, \sigma_{\mathrm{xx}}$, and $\sigma_{\mathrm{xy}}$, were estimated according to the lattice strain variation in different groups of grains at all locations. It is obvious that the stress distributions in yy direction of the (10.0), (10.1), and (11.0) grains were identical during loading-unloading sequence in Fig. 11, suggesting an iso-stress condition in the current study. On the other hand, the shear stress concentrations were more apparent in the (10.0) and (11.0) grains than (00.2) the and (10.1) grains, as displayed in Fig. 12. 


\section{Discussion}

\subsection{Deformation twinning}

It was found that the apparent diffraction peak intensity variation in (10.0) grains was observed in the loading direction in Figs. 4(a)-(d). As mentioned earlier, it has been well established that the $\{10.2\}<10.1>$ extension twinning can be easily activated by tension along caxis and compression perpendicular to the c-axis [15-17, 21, 23-25]. In the present study, no obvious extension twinning occurred during the deformation as illustrated in Figs. 5(i)-(1), mainly because the tensile loading direction is parallel to the $\mathrm{RD}$ of the rolling plate (tension perpendicular to the c-axis). Therefore, it can be deduced that other deformation modes were involved in complex loading conditions, e.g., the current biaxial experimental configuration, leading to the peak intensity changes in (10.0) grains during deformation. By examining the diffraction peak intensity evolution of (00.2) grains induced by all possible twinning modes in Fig. 5 and 6, it was established that the double-twinning, DT1 and DT2, operated intensively compared with the other deformation twinning systems. A certain amount of compression twinning, CT1, was also detected around the notch edge along the loading direction at the maximum load, while only a limited number of CT2 was perceived in Fig. 5. As mentioned earlier, after the formation of the CT1 or CT2 (the $\{10.1\}$ or $\{10.3\}$ contraction twins produced by compressing along the c-axis or pulling perpendicular to the c-axis) the $\{10.2\}$ secondary extension twins will be easily activated in the current loading condition, leading to DT1 or DT2 (the $\{10.1\}-\{10.2\}$ or $\{10.1\}-\{10.2\}$ double twins). Therefore, it can be concluded that nearly all CT2 compression twin grains were transferred to the DT2 double twins, because a large quantity of the DT2 and a small amount of CT2 were observed at the maximum load. On the other hand, the certain amount of CT1 twin grains were retained around the notch, although a large amount 
of DT1 was formed. Moreover, the DT1 and DT2 appeared in the early stage of the deformation in Figs. 6(a) and (e), while the inhabitants of the CT1 and CT2 were very small. It indicates that after the formation of CT1 and CT2, they intended to easily transform into DT1 and DT2 instantaneously even at early stage of deformation. It was revealed that the type 1 and type 2 $\{10.1\}-\{10.2\}$ and $\{10.3\}-\{10.2\}$ double twinning were easily activated during deformation in the current experimental setup, as illustrated in Fig. 6. Among all the deformation twins, the population of type $2\{10.3\}-\{10.2\}$ double twins was largest.

It has been demonstrated that the DT2_T2 disappeared in the center of the notch after the applied load reached $3000 \mathrm{~N}$ in Fig. 6(g). It is most likely that the deformation twinning and/or grain rotation may occur after the formation DT2, due to the high strain/stress concentration in the center of notch edge. The (00.2) plane would rotate out of the diffraction plane, which could not be detected by the 2D detector in the current experimental setup during synchrotron X-ray diffraction measurement. Therefore, the diffraction peak intensity of (00.2) grains vanished in the center of the notch edge.

\subsection{Relationship between macroscopic straining and microscopic response}

In the current study, we took advantage of the specially designed semi-circular notch specimen to investigate the deformation twinning behavior under complex loading conditions. The $\mathrm{R}$ ratio $\left(\varepsilon_{\mathrm{xx}} / \varepsilon_{\mathrm{yy}}\right)$ distribution at $3000 \mathrm{~N}$ measured by DIC is presented in Fig. 13(a). The different strain states based on $\mathrm{R}$ ratio are indicated in Fig. 13(a). It is noticed that there exists a shear band (marked by black dashed circle) inclined in an angle of $34.4^{\circ}$ with the loading direction on the upper left side of Fig. 13(a). The uniaxial strain condition was observed around the center of the notch (marked by black dash-dotted circle), while the combination of the 
uniaxial, biaxial, shear, and plane strains was found in the majority of the sample. It also perceived that the slip bands (marked by purple dotted lines) on the sample surface were under biaxial strain conditions.

It has been acknowledged that the activation of deformation twinning systems greatly depends on the critical resolved shear stress (CRSS) [26, 30, 34]. In the present research, the complex macroscopic localized strain states, as illustrated in Fig. 13, result from the operations of various deformation twinning systems. Comparing Fig. 13(a) with Fig. 5(c), it was found that the retained CT1 is closely related with the pure shear, while a large amount of DT1 was found outside of the shear band in Fig. 6(c). It manifests that the formation of CT1 and the inhibition of transformation from CT1 into the DT1 leads to the macroscopic shear. In Fig. 6(c), it was also realized that the distribution of DT1_T1 inclined in a certain angle, which coincided with the slip bands observed in Fig. 13(a). It designates that the formation of the DT1_T1 contributes to the localized biaxial strain state. A large amount of DT2_T2 was witnessed in the middle the specimen and around the sample notch, as displayed in Fig. 6(g), which correlated with the uniaxial strain condition in Fig. 13(a). It indicates that the formation CT2 as well as the subsequent DT2 produce the uniaxial strain state. It can be summarized that the localized macroscopic strain states are the results of the activation of various deformation twinning modes.

Under the identical macroscopic straining, the biaxial lattice strain states at grain level varied significantly in different $h k l s$. The distributions of biaxial lattice strain states at $3000 \mathrm{~N}$ for certain interested $h k l \mathrm{~s}$ are illustrated in Fig. 13(b)-(e). The ratio of $\varepsilon_{\mathrm{xx}, h k l}$ over $\varepsilon_{\mathrm{yy}, h k l}$ was close to 0 (green color) in the majority of the specimen for the (10.0) and (11.0) grains in Fig. 13(b) and (e), respectively, indicating that the $\varepsilon_{h k l, \mathrm{xx}}$ was much smaller than the $\varepsilon_{h k l, \mathrm{yy}}$. The ratio of $\varepsilon_{h k l, \mathrm{xx}}$ over $\varepsilon_{h k l, y y}$ in the majority of the sample was approximately -0.5 (cyan color) for (00.2) grains, while 
it changed to around 0.5 (yellow color) for the (10.1) grains. It was also noticed that the ratio of $\varepsilon_{h k l, \mathrm{xx}}$ over $\varepsilon_{h k l, \mathrm{yy}}$ was approximately 0 in the (10.0) and (00.2) grains in the shear band where retained CT1 was observed (marked by red lines), as demonstrated in Fig. 13(b) and (c), respectively, while it changed to 0.5 for the (10.1) grains and 0.5 for the (11.0) grains. 


\section{Conclusions}

In situ synchrotron X-ray diffraction mapping has been employed in the current paper to investigate the deformation twinning behavior under complex strain conditions, which were generated by the specially designed semi-circular notch during tension. Main conclusions can be drawn as follows:

(1) The extensive double twins were observed during in situ tension along RD, while nearly no extension twinning activity was detected.

(2) After the formation of type 1 and 2 contraction twins, they transformed into type 1 and 2 double twins immediately at early stage of deformation.

(3) During the loading, the local lattice strain concentrations were observed in the (10.0) and (11.0) grains in the center of the notch in yy direction, while the lattice strain of the (10.1) grains distributed relatively evenly.

(4) After the unloading, a relative large compressive residual strain zone was detected in the (10.1) grains in yy direction close to the notch. For the (10.0) and (11.0) grains, the compressive residual strains were found near to the notch, while the tensile residual strains were witnessed inside the sample.

(5) The localized macroscopic strain states significantly depended on the activation of deformation twinning systems.

(6) The distributions of biaxial lattice strain states were very different in certain interested $h k l s$ under the same macroscopic straining. 


\section{Acknowledgement}

This research used resources at the Spallation Neutron Source (SNS), Oak Ridge National Laboratory (ORNL), supported by the U.S. Department of Energy, Basic Energy Sciences, Scientific User Facilities Division. W.W. is supported by a Laboratory Directed Research and Development (LDRD) project of ORNL. The synchrotron X-ray diffraction work was carried out the Advanced Photon Source, a U.S. Department of Energy (DOE) Office of Science User Facility operated for the DOE Office of Science by Argonne National Laboratory under Contract No. DE-AC02-06CH11357. 


\section{References}

[1] I.J. Polmear, Magnesium alloys and applications, Mater. Sci. Technol. 10 (1994) 1-16.

[2] B.C. Suh, M.S. Shim, K.S. Shin, N.J. Kim, Current issues in magnesium sheet alloys: Where do we go from here?, Scr. Mater. 84-85 (2014) 1-6.

[3] L.J. Chen, C.Y. Wang, W. Wu, Z. Liu, G.M. Stoica, L. Wu, P.K. Liaw, Low-cycle fatigue behavior of an as-extruded AM50 magnesium alloy, Metall. Mater. Trans. A 38A (2007) 2235-2241.

[4] F.A. Mirza, D.L. Chen, D.J. Li, X.Q. Zeng, Low cycle fatigue of a rare-earth containing extruded magnesium alloy, Mater. Sci. Eng. A 575 (2013) 65-73.

[5] S.R. Agnew, R.P. Mulay, F.J. Polesak, C.A. Calhoun, J.J. Bhattacharyya, B. Clausen, In situ neutron diffraction and polycrystal plasticity modeling of a $\mathrm{Mg}-\mathrm{Y}-\mathrm{Nd}-\mathrm{Zr}$ alloy: Effects of precipitation on individual deformation mechanisms, Acta Mater. 61 (2013) 3769-3780.

[6] S.Y. Lee, H. Wang, M.A. Gharghouri, G. Nayyeri, W. Woo, E. Shin, P.D. Wu, W.J. Poole, W. Wu, K. An, Deformation behavior of solid-solution-strengthened Mg-9 wt.\% Al alloy: In situ neutron diffraction and elastic-viscoplastic self-consistent modeling, Acta Mater. 73 (2014) 139-148.

[7] A. Jain, O. Duygulu, D.W. Brown, C.N. Tome, S.R. Agnew, Grain size effects on the tensile properties and deformation mechanisms of a magnesium alloy, AZ31B, sheet, Mater. Sci. Eng. A 486 (2008) 545-555.

[8] R. Zhu, W.Q. Ji, Y.J. Wu, X.T. Cai, Y. Yu, Effect of aging treatment on low-cycle fatigue behavior of extruded Mg-8Al-0.5Zn alloys, Mater. Des. 41 (2012) 203-207.

[9] W.C. Liu, G.H. Wu, C.Q. Zhai, W.J. Ding, A.M. Korsunsky, Grain refinement and fatigue strengthening mechanisms in as-extruded $\mathrm{Mg}-6 \mathrm{Zn}-0.5 \mathrm{Zr}$ and $\mathrm{Mg}-10 \mathrm{Gd}-3 \mathrm{Y}-0.5 \mathrm{Zr}$ magnesium alloys by shot peening, Int. J. Plast. 49 (2013) 16-35.

[10] M.R. Barnett, Z. Keshavarz, A.G. Beer, D. Atwell, Influence of grain size on the compressive deformation of wrought Mg-3Al-1Zn, Acta Mater. 52 (2004) 5093-5103.

[11] S.R. Agnew, O. Duygulu, Plastic anisotropy and the role of non-basal slip in magnesium alloy AZ31B, Int. J. Plast. 21 (2005) 1161-1193.

[12] X.Y. Lou, M. Li, R.K. Boger, S.R. Agnew, R.H. Wagoner, Hardening evolution of AZ31B Mg sheet, Int. J. Plast. 23 (2007) 44-86.

[13] O. Muransky, D.G. Carr, P. Sittner, E.C. Oliver, In situ neutron diffraction investigation of deformation twinning and pseudoelastic-like behaviour of extruded AZ31 magnesium alloy, Int. J. Plast. 25 (2009) 1107-1127.

[14] G. Proust, C.N. Tome, A. Jain, S.R. Agnew, Modeling the effect of twinning and detwinning during strain-path changes of magnesium alloy AZ31, Int. J. Plast. 25 (2009) 861-880.

[15] L. Wu, S.R. Agnew, D.W. Brown, G.M. Stoica, B. Clausen, A. Jain, D.E. Fielden, P.K. Liaw, Internal stress relaxation and load redistribution during the twinning-detwinningdominated cyclic deformation of a wrought magnesium alloy, ZK60A, Acta Mater. 56 (2008) 3699-3707.

[16] L. Wu, A. Jain, D.W. Brown, G.M. Stoica, S.R. Agnew, B. Clausen, D.E. Fielden, P.K. Liaw, Twinning-detwinning behavior during the strain-controlled low-cycle fatigue testing of a wrought magnesium alloy, ZK60A, Acta Mater. 56 (2008) 688-695. 
[17] L. Wu, S.R. Agnew, Y. Ren, D.W. Brown, B. Clausen, G.M. Stoica, H.R. Wenk, P.K. Liaw, The effects of texture and extension twinning on the low-cycle fatigue behavior of a rolled magnesium alloy, AZ31B, Mater. Sci. Eng. A 527 (2010) 7057-7067.

[18] W. Wu, S.Y. Lee, A.M. Paradowska, Y.F. Gao, P.K. Liaw, Twinning-detwinning behavior during fatigue-crack propagation in a wrought magnesium alloy AZ31B, Mater. Sci. Eng. A 556 (2012) 278-286.

[19] O. Muransky, M.R. Barnett, D.G. Carr, S.C. Vogel, E.C. Oliver, Investigation of deformation twinning in a fine-grained and coarse-grained ZM20 Mg alloy: Combined in situ neutron diffraction and acoustic emission, Acta Mater. 58 (2010) 1503-1517.

[20] S.R. Agnew, C.N. Tome, D.W. Brown, T.M. Holden, S.C. Vogel, Study of slip mechanisms in a magnesium alloy by neutron diffraction and modeling, Scr. Mater. 48 (2003) 1003-1008.

[21] W. Wu, K. An, L. Huang, S.Y. Lee, P.K. Liaw, Deformation dynamics study of a wrought magnesium alloy by real-time in situ neutron diffraction, Scr. Mater. 69 (2013) 358-361.

[22] X.Q. Guo, W. Wu, P.D. Wu, H. Qiao, K. An, P.K. Liaw, On the Swift effect and twinning in a rolled magnesium alloy under free-end torsion, Scr. Mater. 69 (2013) 319322.

[23] W. Wu, P.K. Liaw, K. An, Unraveling cyclic deformation mechanisms of a rolled magnesium alloy using in situ neutron diffraction, Acta Mater. 85 (2015) 343-353.

[24] W. Wu, H. Qiao, K. An, X. Guo, P. Wu, P.K. Liaw, Investigation of deformation dynamics in a wrought magnesium alloy, Int. J. Plast. 62 (2014) 105-120.

[25] W. Wu, K. An, Understanding low-cycle fatigue life improvement mechanisms in a pretwinned magnesium alloy, J. Alloys Compd. 656 (2016) 539-550.

[26] É. Martin, L. Capolungo, L. Jiang, J.J. Jonas, Variant selection during secondary twinning in Mg-3\%Al, Acta Mater. 58 (2010) 3970-3983.

[27] D. Ando, J. Koike, Y. Sutou, Relationship between deformation twinning and surface step formation in AZ31 magnesium alloys, Acta Mater. 58 (2010) 4316-4324.

[28] M.R. Barnett, Z. Keshavarz, A.G. Beer, X. Ma, Non-Schmid behaviour during secondary twinning in a polycrystalline magnesium alloy, Acta Mater. 56 (2008) 5-15.

[29] I.J. Beyerlein, J. Wang, M.R. Barnett, C.N. Tomé, Double twinning mechanisms in magnesium alloys via dissociation of lattice dislocations, P. Roy. Soc. Lond. A Mat. (2012).

[30] S.H. Park, S.-G. Hong, J.H. Lee, C.S. Lee, Multiple twinning modes in rolled Mg-3Al1Zn alloy and their selection mechanism, Mater. Sci. Eng. A 532 (2012) 401-406.

[31] B.-C. Suh, M.-S. Shim, D.-W. Kim, N.J. Kim, Twinning behavior of Mg-4Zn-1Gd alloy sheet during longitudinal tensile deformation, Scr. Mater. 69 (2013) 465-468.

[32] B.B. He, Stress measurement with two-dimensional diffraction, P. Int. Cong. Experit. M. (2000) 943-945.

[33] B.B. He, Two-dimensional x-ray diffraction, Wiley, 2009.

[34] M.A. Gharghouri, G.C. Weatherly, J.D. Embury, J. Root, Study of the mechanical properties of Mg-7.7at.\% Al by in-situ neutron diffraction, Philos. Mag. A 79 (1999) 1671-1695. 


\section{Figure Captions}

Table 1. Deformation twinning systems in HCP-structured Mg alloy.

Table 2. The four types of $\{10-11\}-\{10-12\}$ double twinning in HCP-structured Mg alloy.

Table 3. The four types of $\{10-13\}-\{10-12\}$ double twinning in HCP-structured Mg alloy.

Table 4. The material parameters achieved from neutron diffraction results.

Figure 1. (a) Sample geometry and mapping area of semi-circular notched plate dog bone specimen. (b) and (c) The simulation and experimental results, respectively, of (00.2) peak intensity distribution before and after deformation.

Figure 2. Schematics of grain reorientation due to different deformation twinning systems in HCP-structured material.

Figure 3. Digital image correlation results of $\varepsilon_{\mathrm{yy}}, \varepsilon_{\mathrm{xx}}$, and $\varepsilon_{\mathrm{xy}}$ at different load levels.

Figure 4. Diffraction peak intensity distribution of (10.0) and (00.2) grains in yy and xx directions. The letters $\mathrm{A}$ and $\mathrm{T}$ stand for the axial and transverse directions of specimen, respectively.

Figure 5. The evolution of diffraction peak intensity in (00.2) grains induced by different twinning modes.

Figure 6. The variation of diffraction peak intensity in (00.2) grains caused by four different types of $\{10-11\}-\{10-12\}$ double twinning.

Figure 7. The lattice strain variation of (10.0) and (00.2) in yy and xx directions, respectively, along the notch.

Figure 8. The averaged lattice strain variation in (10.0) and (00.2) grains in yy and $\mathrm{xx}$ directions at different locations.

Figure 9. The lattice strain distribution of certain $h \mathrm{kls}$ in loading and transverse directions at different load levels.

Figure 10. The lattice strain distribution of certain $h \mathrm{kls}$ in shear direction at different load levels.

Figure 11. The calculated stress distribution in certain $h \mathrm{kls}$ in loading and transverse directions at different load levels.

Figure 12. The calculated stress distribution in certain $h k l s$ in shear direction at different load levels. 
Figure 13. (a) The calculated R-ratio $\left(\varepsilon_{\mathrm{xx}} / \varepsilon_{\mathrm{yy}}\right)$ distribution at $3000 \mathrm{~N}$ by DIC. (b)-(e) The distribution of biaxial lattice strain states $\left(\varepsilon_{h k l, \mathrm{xx}} / \varepsilon_{h k l, \mathrm{yy}}\right)$ at $3000 \mathrm{~N}$ for $(10.0),(00.2)$, (10.1), and (11.0) grains, respectively. 
Table 1. Deformation twinning systems in HCP-structured Mg alloy.

\begin{tabular}{|l|l|l|}
\hline Type of twin & Twin plane & Misorientation angle \\
\hline Extension twinning (ET) & $\{10-12\}$ & $86.3^{\circ}$ \\
\hline Contraction twinning (CT1) & $\{10-11\}$ & $56.2^{\circ}$ \\
\hline Contraction twinning (CT2) & $\{10-13\}$ & $64^{\circ}$ \\
\hline Double twinning (DT1) & $\{10-11\}-\{10-12\}$ & $37.5^{\circ}$ \\
\hline Double twinning (DT2) & $\{10-13\}-\{10-12\}$ & $22^{\circ}$ \\
\hline
\end{tabular}


Table 2. The four types of $\{10-11\}-\{10-12\}$ double twinning in HCP-structured Mg alloy.

\begin{tabular}{|l|l|l|}
\hline Double twinning (DT1) & Twin plane & Misorientation angle \\
\hline Type 1 (DT1_T1) & $(-1011)-(-1012)$ & $37.5^{\circ}$ \\
\hline Type 2 (DT1_T2) & $(-1011)-(10-12)$ & $30.1^{\circ}$ \\
\hline Type 3 (DT1_T3) & $\begin{array}{l}(-1011)-(1-102) \\
(-1011)-(01-12)\end{array}$ & $66.5^{\circ}$ \\
\hline Type 4 (DT1_T4) & $\begin{array}{l}(-1011)-(-1102) \\
(-1011)-(0-112)\end{array}$ & $69.9^{\circ}$ \\
\hline
\end{tabular}


Table 3. The four types of $\{10-13\}-\{10-12\}$ double twinning in HCP-structured Mg alloy.

\begin{tabular}{|l|l|l|}
\hline Double twinning (DT2) & Twin plane & Misorientation angle \\
\hline Type 1 (DT2_T1) & $(-1013)-(-1012)$ & $30^{\circ}$ \\
\hline Type 2 (DT2_T2) & $(-1013)-(10-12)$ & $22^{\circ}$ \\
\hline Type 3 (DT2_T3) & $\begin{array}{l}(-1013)-(1-102) \\
(-1013)-(01-12)\end{array}$ & $46.3^{\circ}$ \\
\hline Type 4 (DT2_T4) & $\begin{array}{l}(-1013)-(-1102) \\
(-1013)-(0-112)\end{array}$ & $46.5^{\circ}$ \\
\hline
\end{tabular}


Table 4. The material parameters achieved from neutron diffraction results.

\begin{tabular}{|l|l|l|}
\hline $\boldsymbol{h} \boldsymbol{k} . \boldsymbol{l}$ & $\begin{array}{l}\text { Young's Modulus } \\
\left(\mathbf{E}^{\text {hk.l }}, \mathbf{G P a}\right)\end{array}$ & $\begin{array}{l}\text { Poisson's ratio } \\
\left(\boldsymbol{v}_{\text {hk.l }}\right)\end{array}$ \\
\hline 10.0 & 39.678 & 0.2681 \\
\hline 00.2 & 51.334 & 0.3423 \\
\hline 10.1 & 50.540 & 0.2353 \\
\hline 11.0 & 39.887 & 0.2323 \\
\hline
\end{tabular}




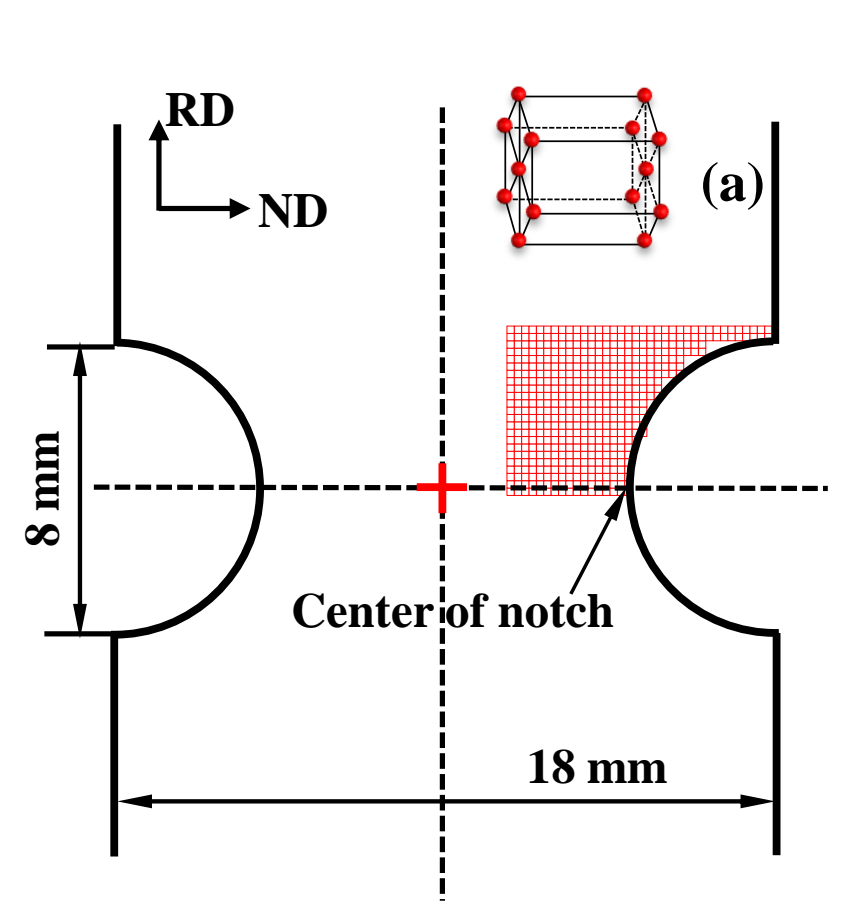

Thickness: $2.5 \mathrm{~mm}$

Beam size: $0.2 \times 0.2 \mathrm{~mm}^{2}$ Step size: $0.2 \mathrm{~mm}$
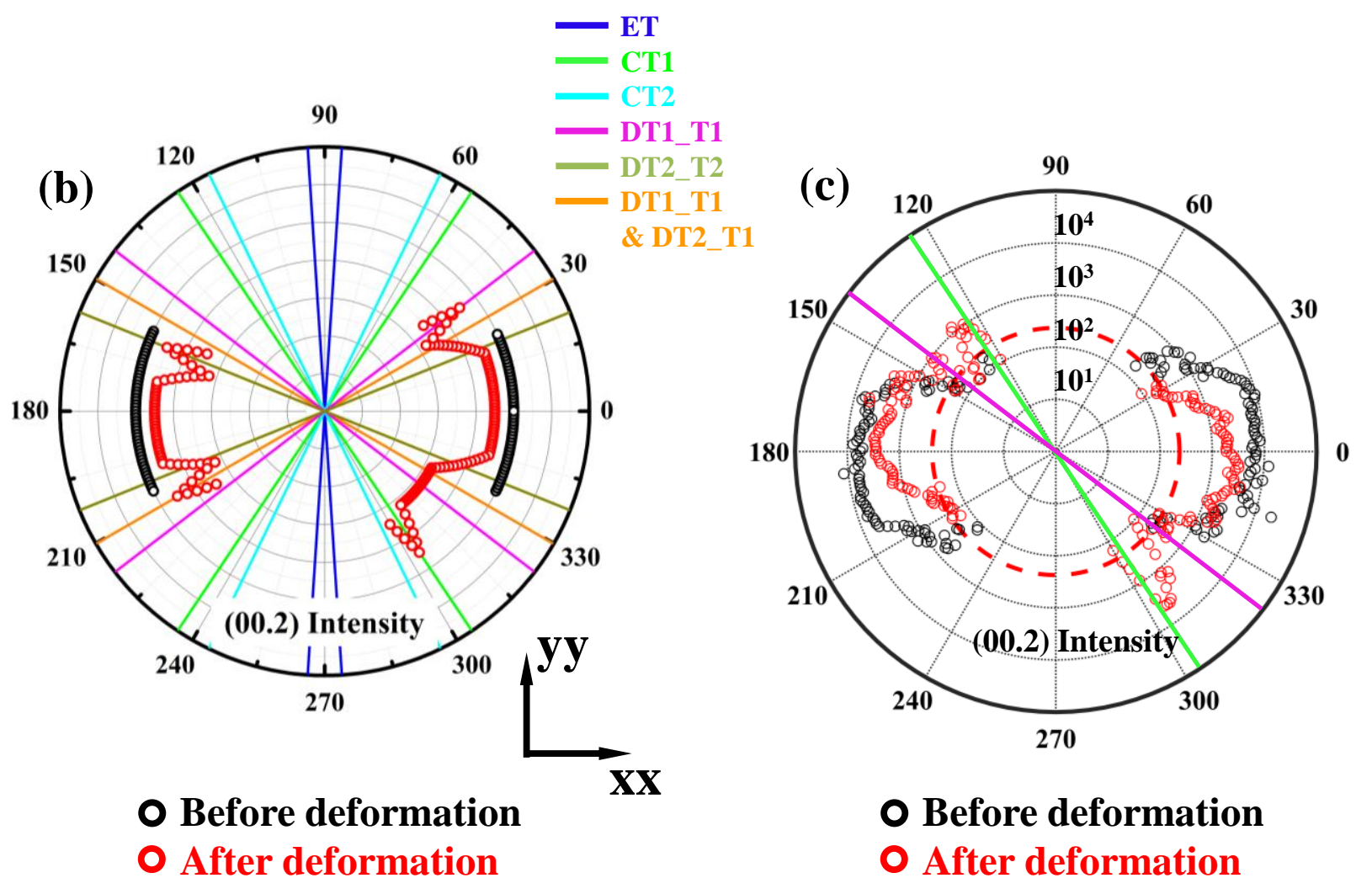

O Before deformation

- After deformation 
Figure 4

0 N

3000 N

0 N
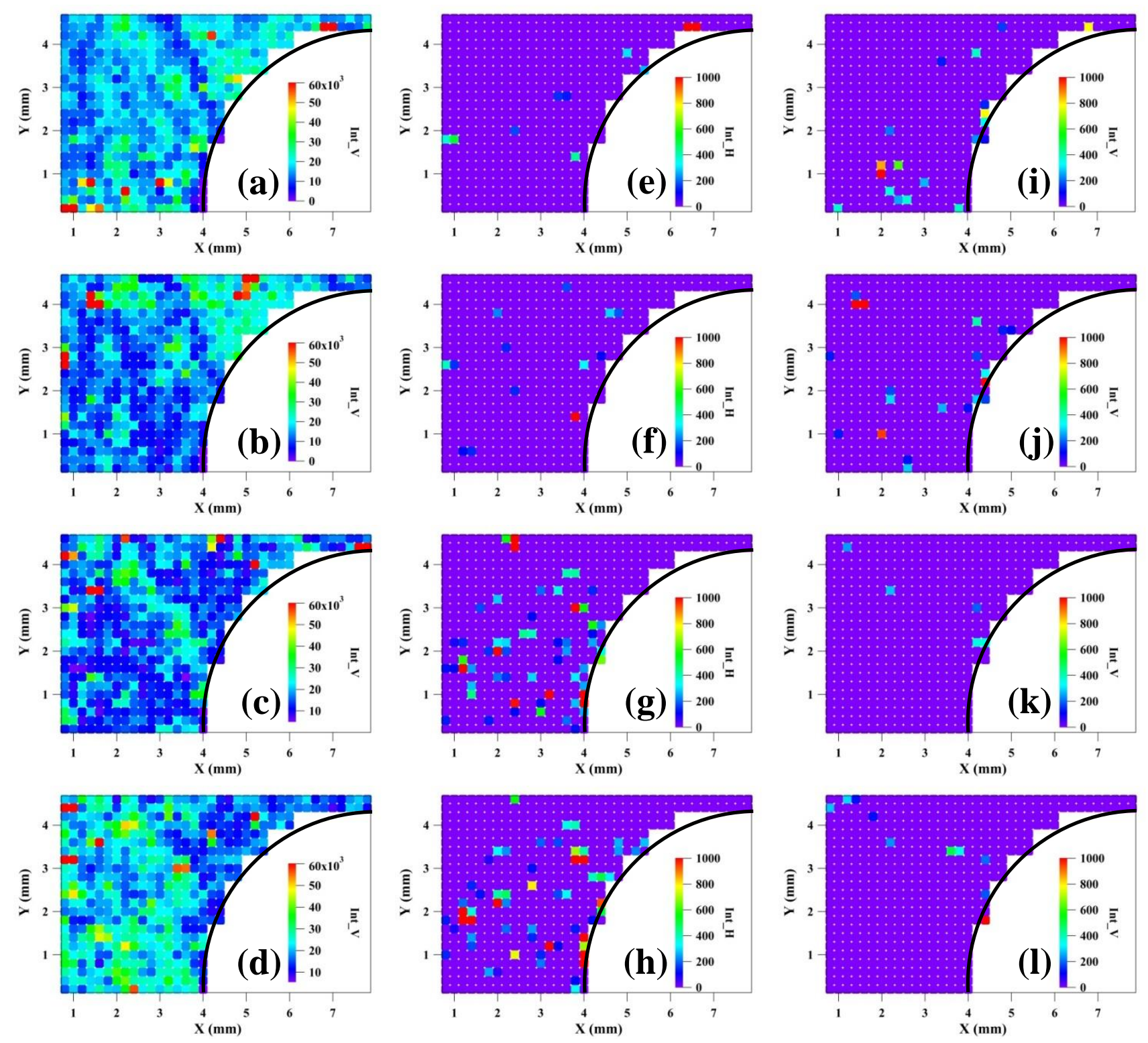

(10.0) Intensity-A

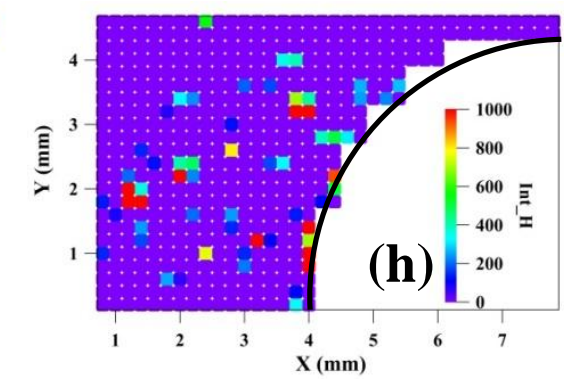

(10.0) Intensity-T
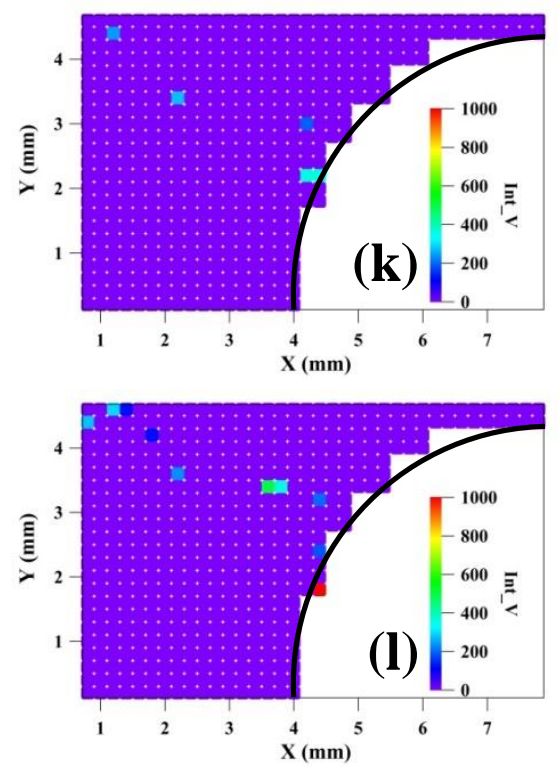

(00.2) Intensity-A
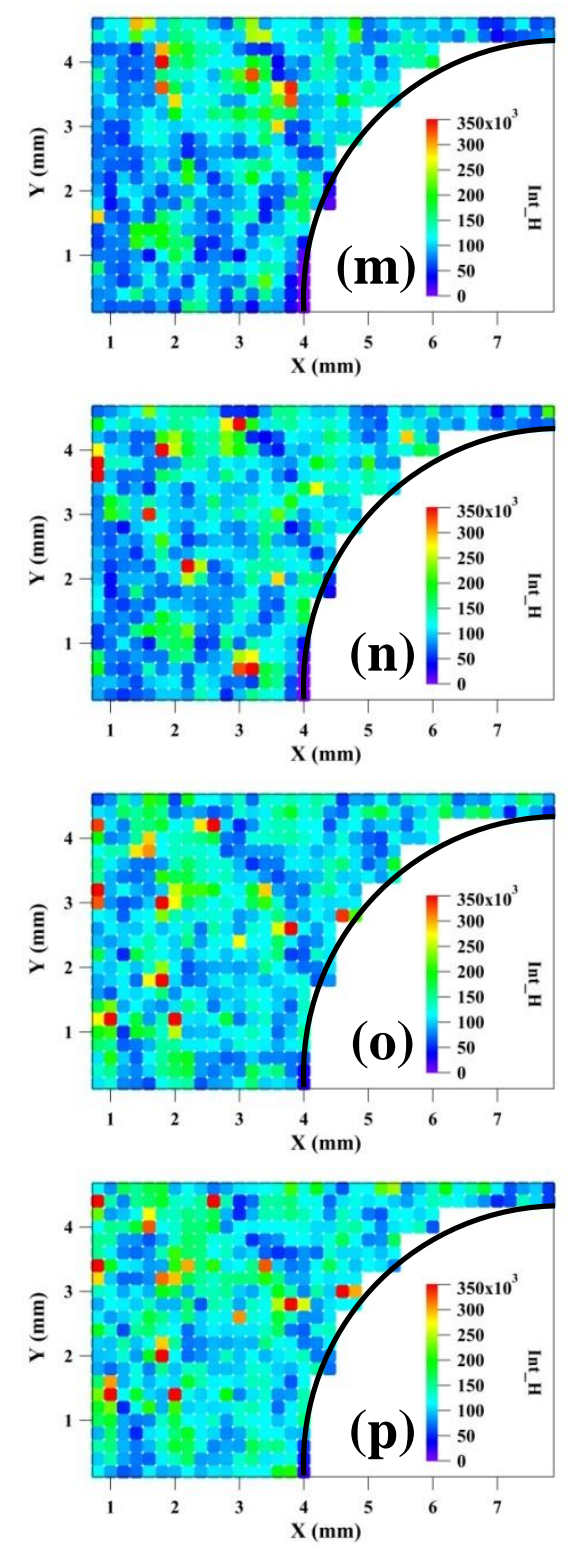

(00.2) Intensity-T 

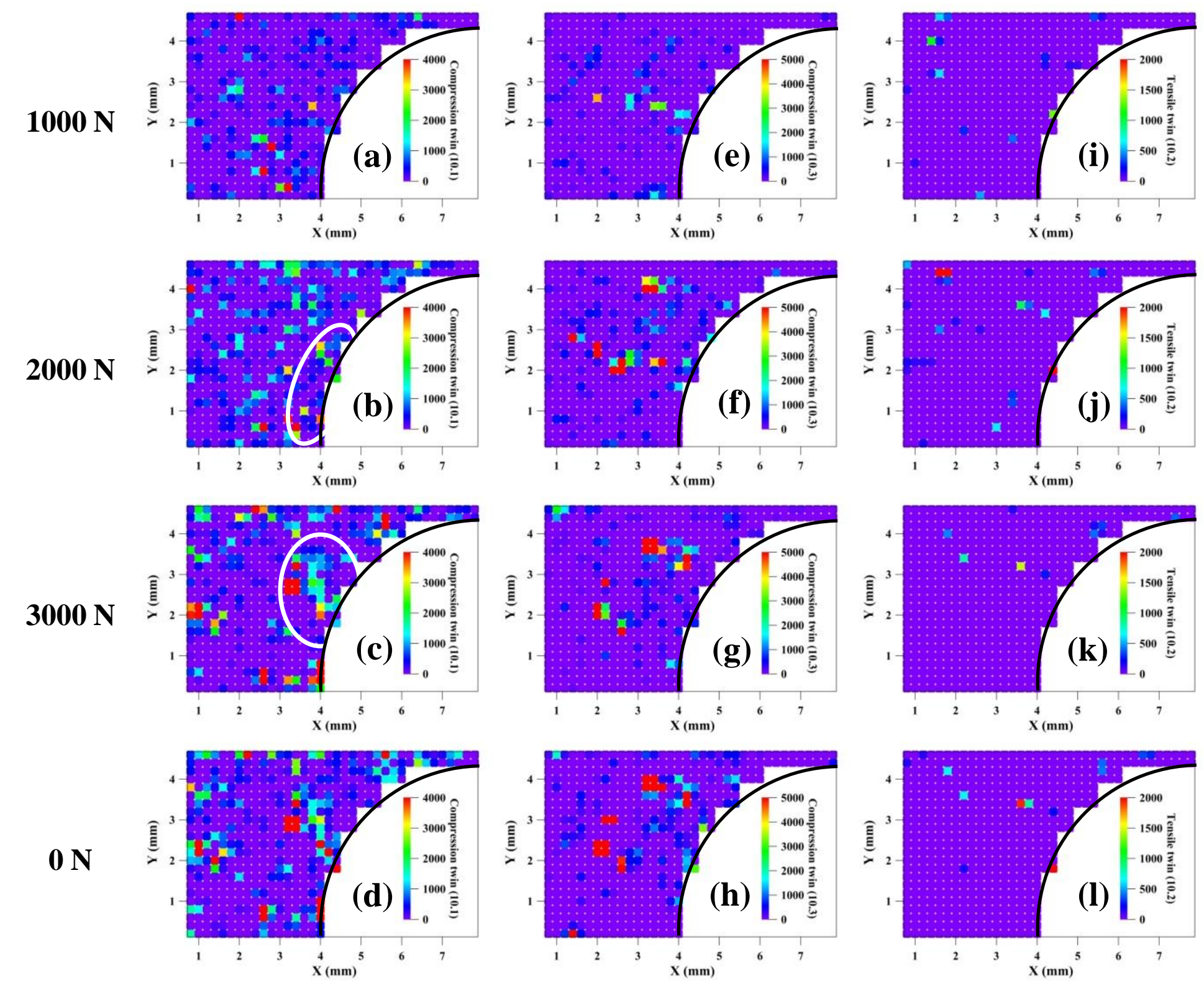

CT1

CT2

ET 

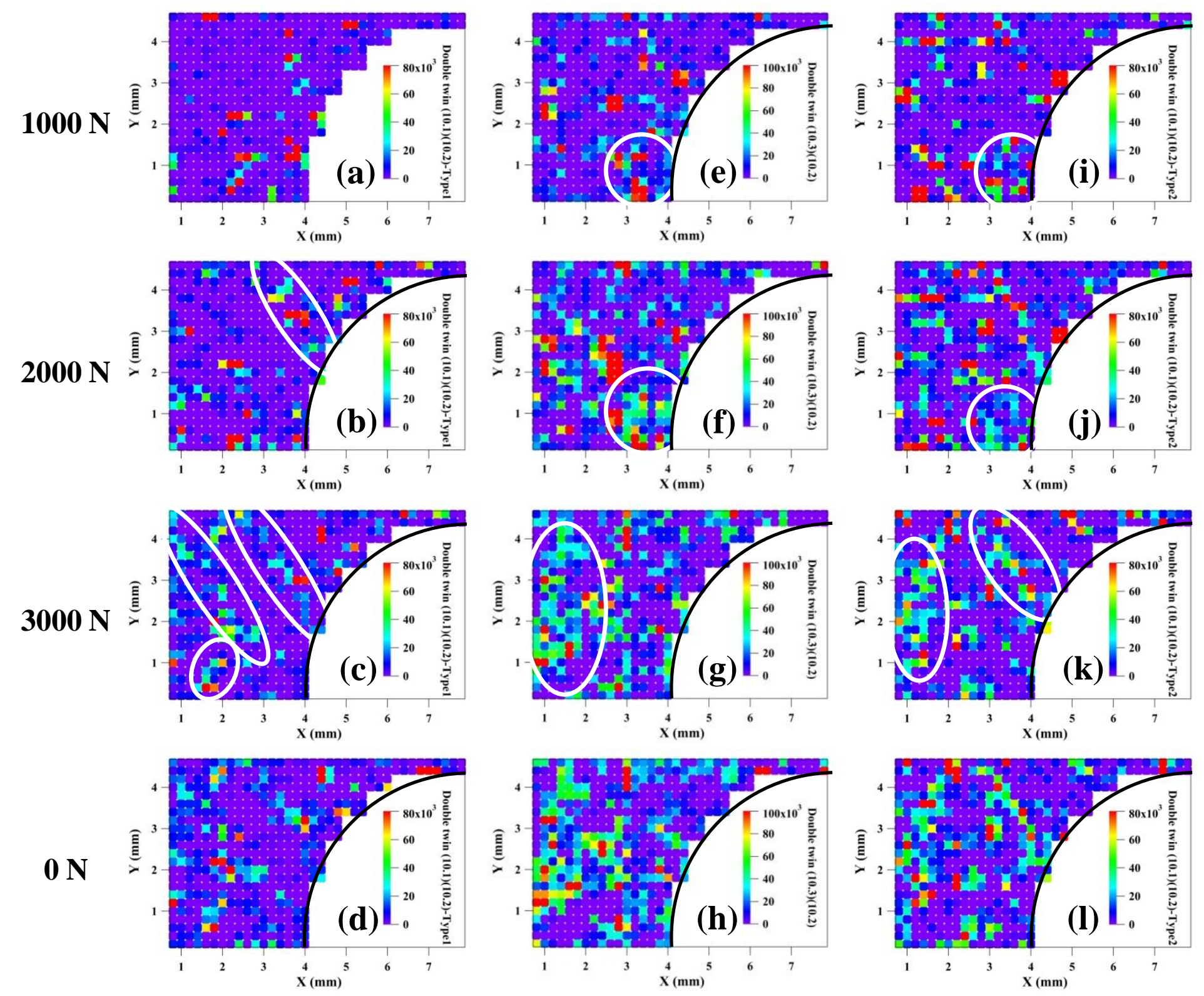

DT1_T1

DT2_T2

DT1_T2 \& DT2_T1 


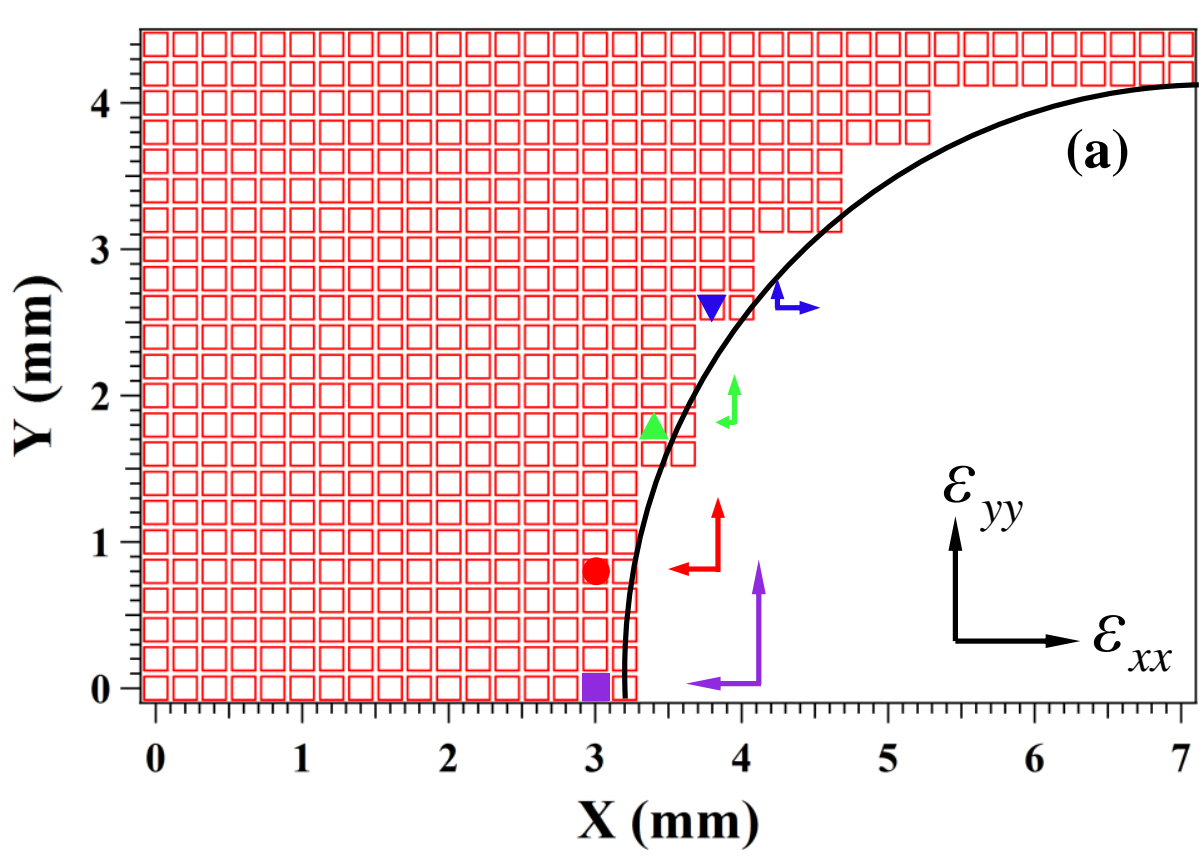

The (10.0) peak, $\varepsilon_{\mathrm{yy}}$

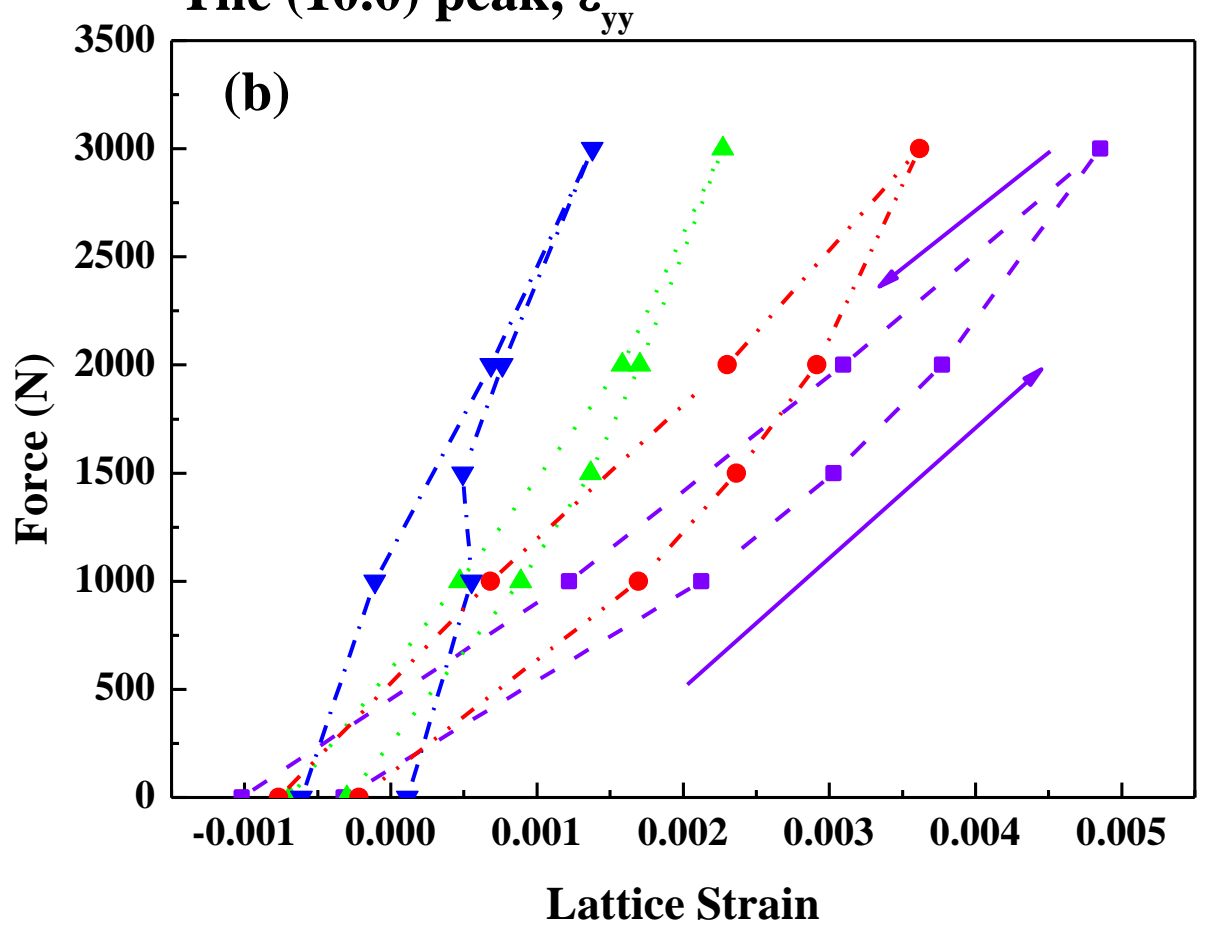

The $(00.2)$ peak, $\varepsilon_{\mathrm{xx}}$

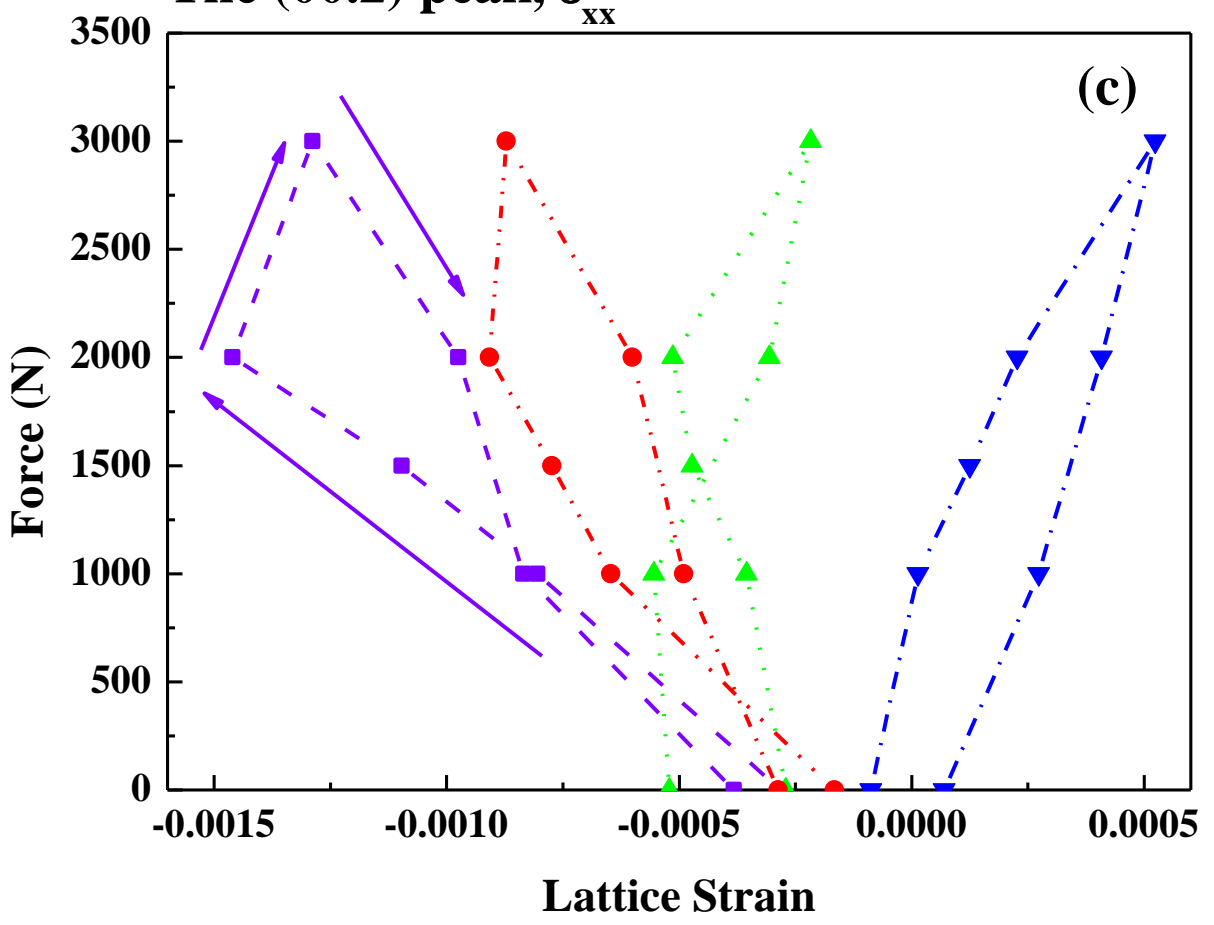


The $(10.0)$ peak, $\varepsilon_{y y}$

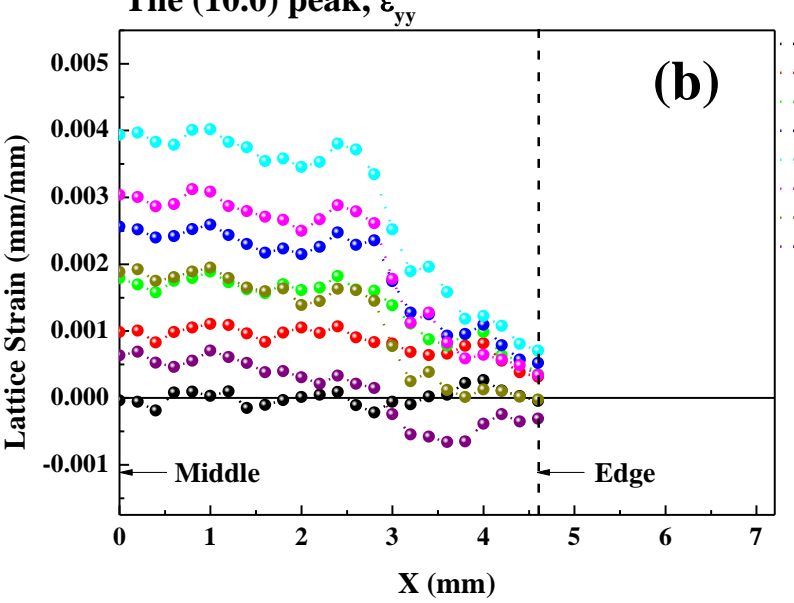

The $(10.0)$ peak, $\varepsilon_{y y}$

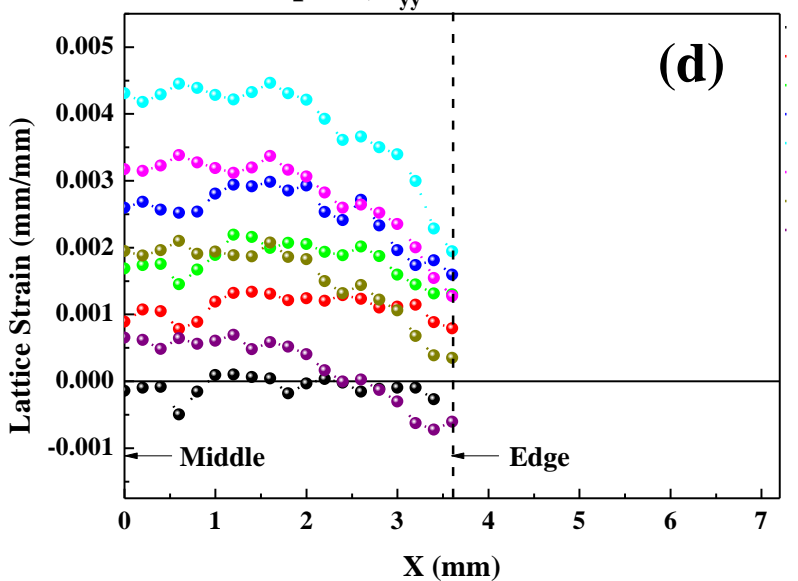

(a)
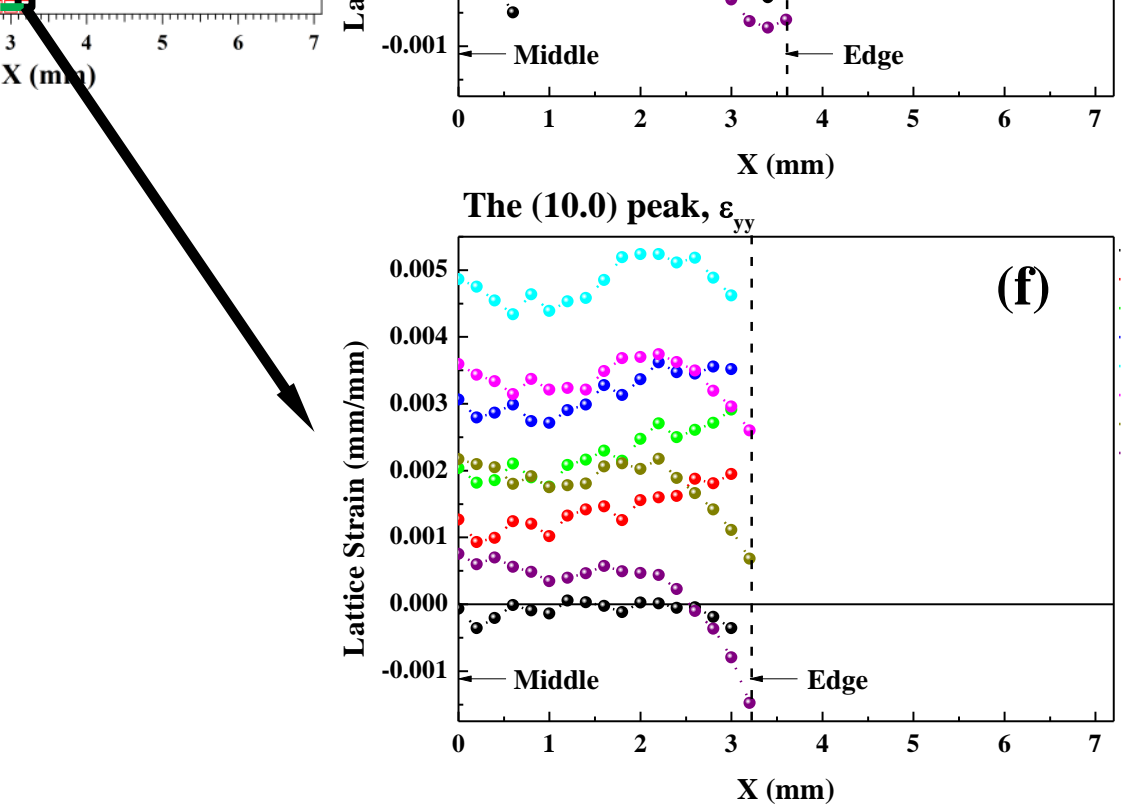

$\mathbf{X}(\mathbf{m m})$
The (00.2) peak, $\varepsilon_{\mathrm{xx}}$

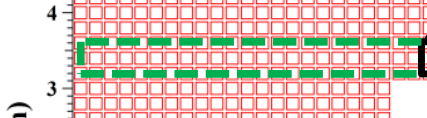

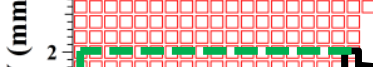

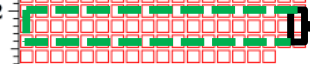

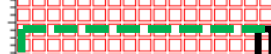

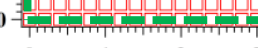

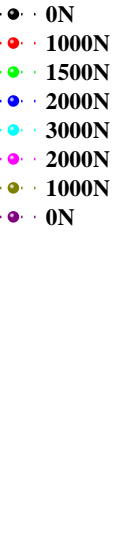

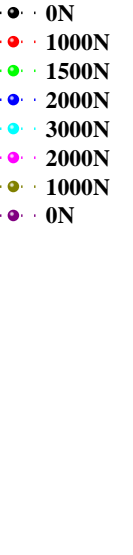

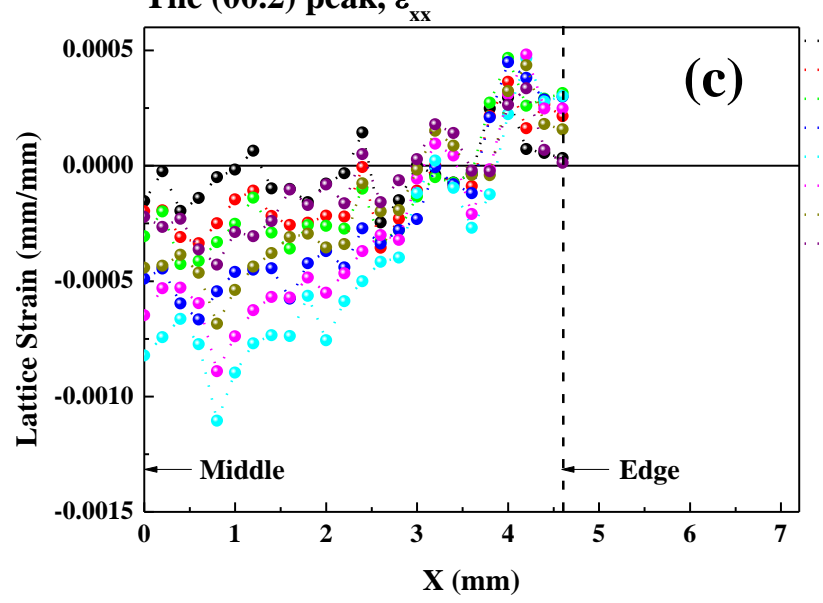

- $0 \mathrm{~N}$

$1000 \mathrm{~N}$

- $2000 \mathrm{~N}$

$3000 \mathrm{~N}$
$2000 \mathrm{~N}$

$1000 \mathrm{~N}$

- $0 \mathrm{~N}$

The (00.2) peak, $\varepsilon_{\mathrm{xx}}$

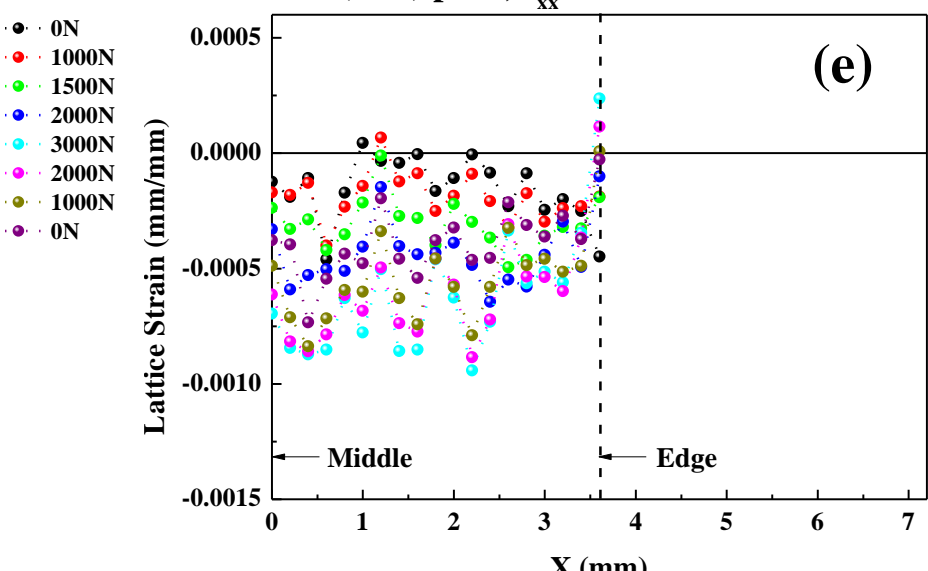

$\mathbf{0 N}$

- . $1000 \mathrm{~N}$

$2000 \mathrm{~N}$

$3000 \mathrm{~N}$

$2000 \mathrm{~N}$

$1000 \mathrm{~N}$

- $0 \mathrm{~N}$ 

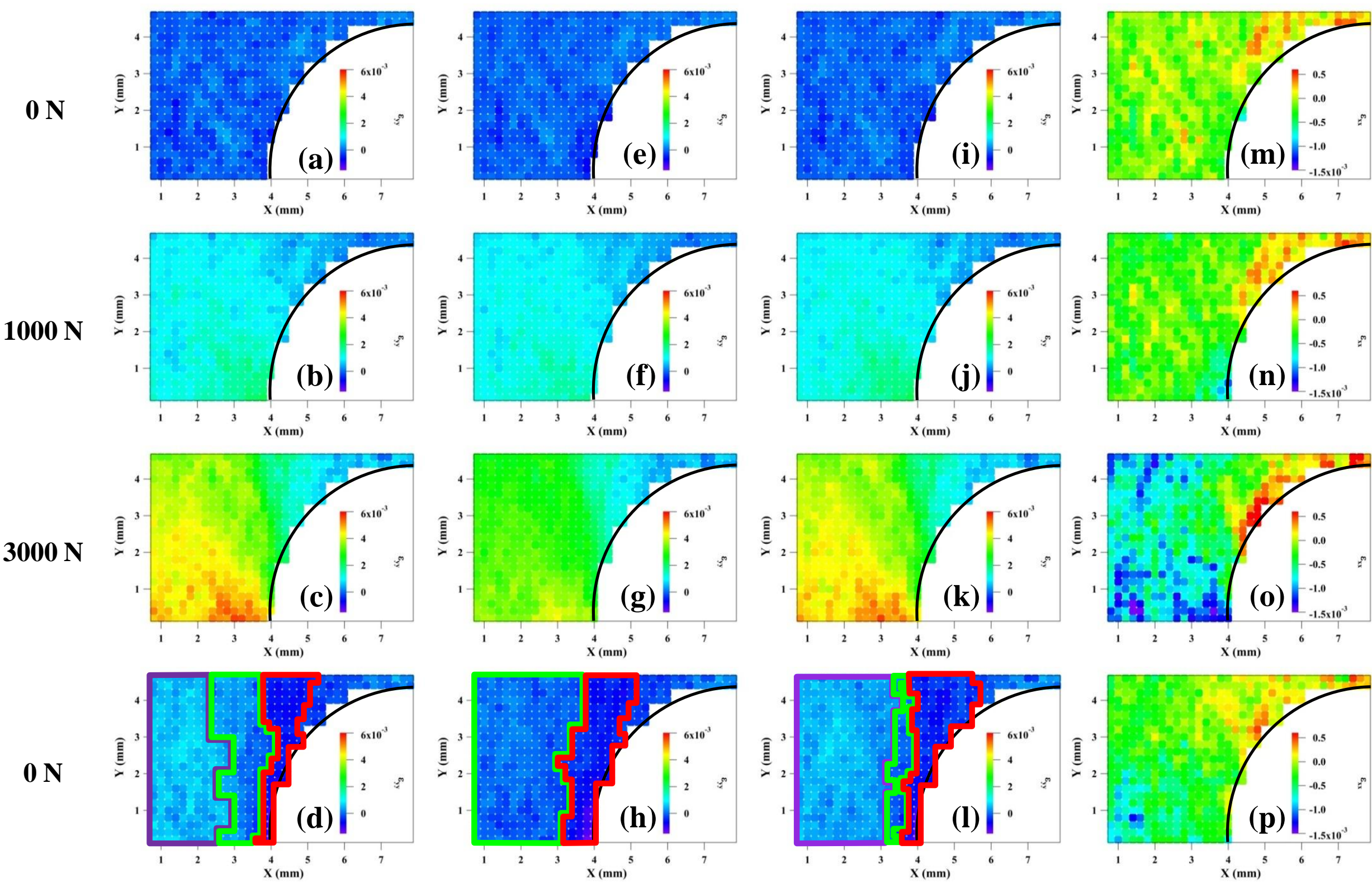

$\varepsilon_{y y}^{(10.0)}$

$\varepsilon_{y y}^{(10.1)}$

$\varepsilon_{y y}^{(11.0)}$

$\varepsilon_{x x}^{(00.2)}$ 

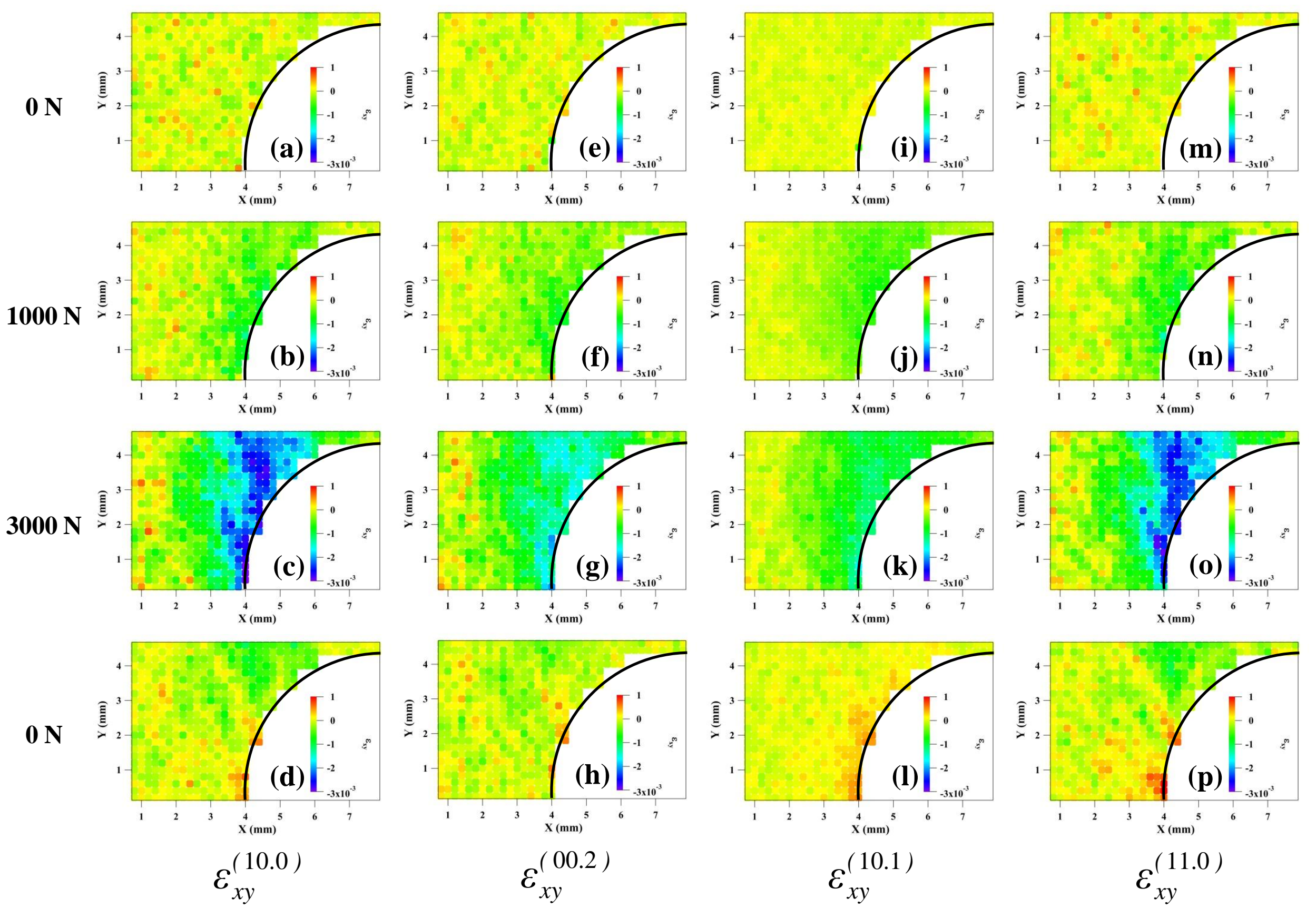
Figure 11

\section{Figure 11}
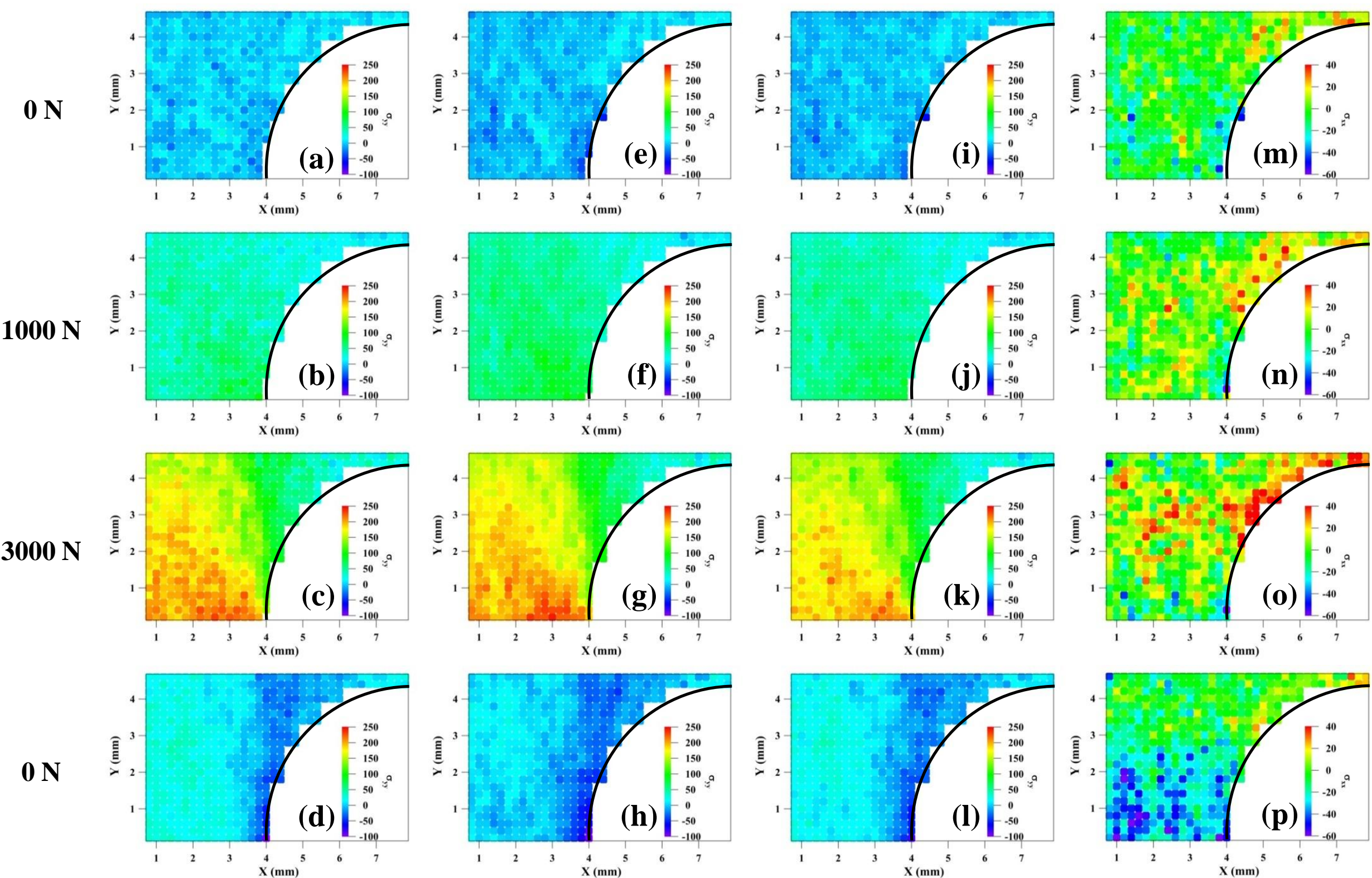

$$
\sigma_{y y}^{(10.0)}
$$

$$
\sigma_{y y}^{(10.1)}
$$

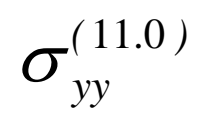

$$
\sigma_{x x}^{(00.2)}
$$



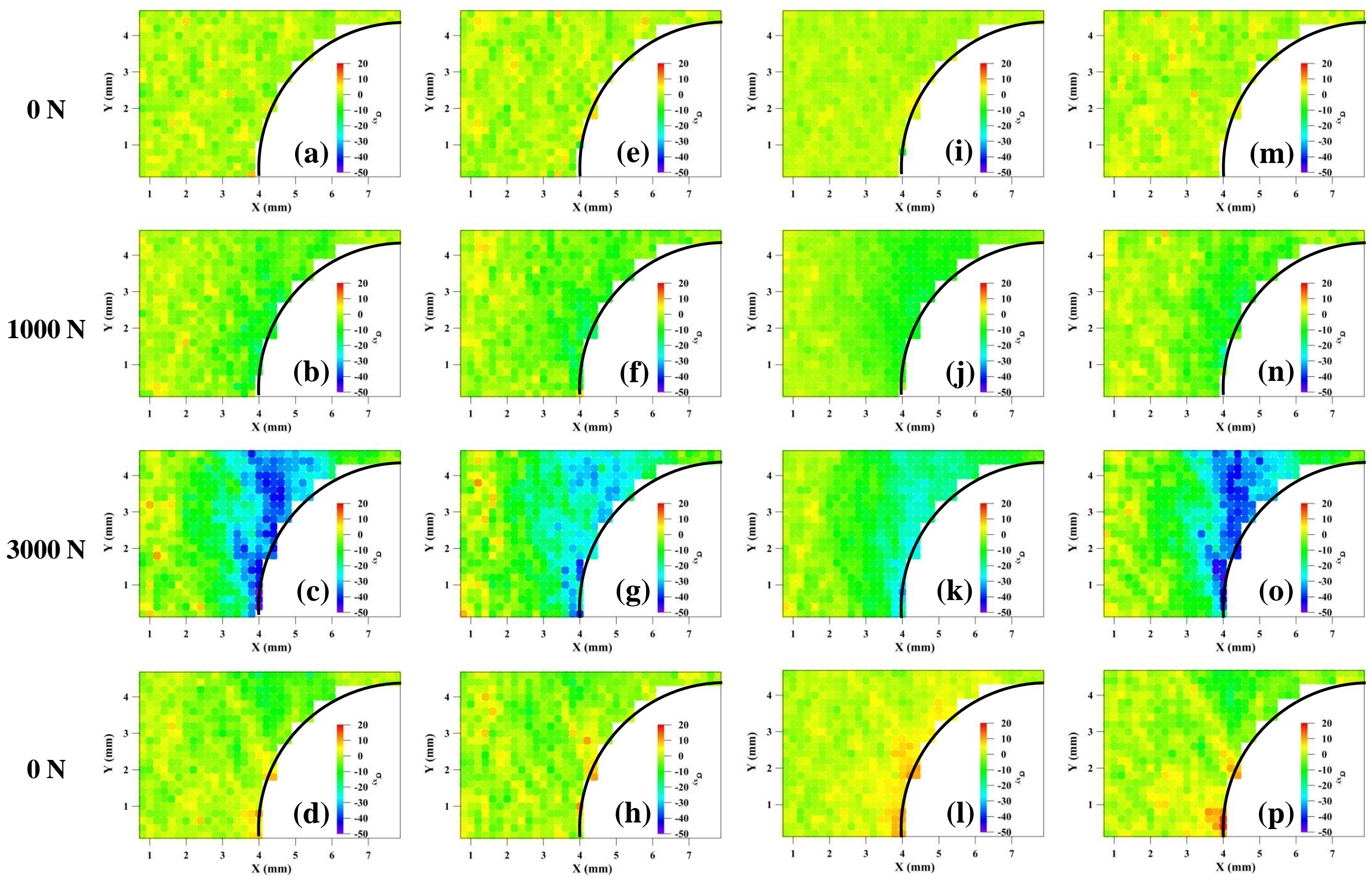

$$
\tau_{x y}^{(10.0)}
$$

$$
\tau_{x y}^{(00.2)}
$$

$$
\tau_{x y}^{(10.1)}
$$

$$
\tau_{x y}^{(11.0)}
$$


